\title{
Face dependent footprints of carpet-like graphene films grown on polycrystalline silicon carbide
}

\author{
C. Ramírez, ${ }^{1}$ E. García, ${ }^{1}$ E. Barrena, ${ }^{2}$ A. De Pablos, ${ }^{1}$ M. Belmonte, ${ }^{1}$ M.I. Osendi, ${ }^{1}$ \\ P. Miranzo, ${ }^{1 *}$ C. Ocal ${ }^{2 \dagger}$ \\ ${ }^{1}$ Instituto de Cerámica y Vidrio (ICV-CSIC), Campus de Cantoblanco, 28049 Madrid, \\ Spain \\ ${ }^{2}$ Institut de Ciència de Materials de Barcelona (ICMAB-CSIC) \\ Campus UAB, 08193 Bellaterra, Barcelona, Spain
}

$\S$ Present address: Center for Thermal Spray Research, Stony Brook University, Stony Brook, 11794-2275, NY, USA.

\footnotetext{
"Corresponding author: Tel:+34-917355840 E-mail: pmiranzo@icv.csic.es (Pilar Miranzo)

+ Corresponding author: Tel:+34-935801853. E-mail: cocal@icmab.es (Carmen Ocal)
} 


\begin{abstract}
Continuous epitaxial graphene (EG) films have been grown on polished surfaces of dense polycrystalline $\mathrm{SiC}$ ceramics by heating in a Spark Plasma Sintering furnace (SPS). The confining of the sample into a graphite die and the use of a high pulsed dc current that triggers the joule heating of the system play a key role in the graphene formation by $\mathrm{Si}$ sublimation. The polycrystalline nature of the sample has allowed the comparison, through different local probe microscopies and micro-Raman spectroscopy, between EG films simultaneously grown on different $\mathrm{SiC}$ faces at exactly the same conditions, providing valuable information on their thickness, quality and stresses. Notably, whereas a graphene bilayer grows over Si-face grains, multilayer graphene ( $\sim 10$ layers) forms on C-faces. The observed nano-electronic and nano-mechanical heterogeneities of the surface, showing up as differences in charge state and strain release mechanisms, are found to arise from the dependence of the EG properties when developed on each grain orientation; the same applies in the case of the macro-mechanical scratch resistance. SPS demonstrates to be a reliable and flexible methodology to prepare continuous graphene films on $\mathrm{SiC}$ components with many possibilities for scaling-up at low cost.
\end{abstract}

\title{
1. Introduction
}

Although the unique properties of graphene are mainly attributed to its $2 \mathrm{D}$ structure, graphene cannot stand alone without a supporting substrate in real applications and, then, it usually appears in combination with substrates of different nature. Therefore, the interaction of graphene with the substrate used for its growth, as well as its transfer to another substrate for the targeted application, have become critical research topics [1,2]. Several methods can be found for large area production of graphene films/coatings, comprising solution-based deposition methods, electrophoretic deposition (EPD) and chemical vapor deposition (CVD) [3,4,5]. For the first ones, where we may include dip, layer-by-layer, spray and spin coating, it is difficult to control the thickness and uniformity of the graphene-based thin film while EPD and CVD require conducting substrates. Conversely, the sublimation of silicon carbide ( $\mathrm{SiC})$ allows developing large-area, low- 
defect-density epitaxial graphene (EG) films that are directly grown on both the Si-face and the $\mathrm{C}$-face of $\mathrm{SiC}$ single crystals [6,7]. In this approach, $\mathrm{Si}$ atoms sublimates off and the remaining carbon atoms rearranges in a honeycomb $2 \mathrm{D}$ pattern. It should be pointed out that polycrystalline $\mathrm{SiC}$ ceramics are notable structural and wear resistant materials, which are commonly used in advanced technological applications, most importantly, where mechanical engineering devices and components are required to operate at elevated temperatures (valves, mechanical seals, bearings, and thermal management and storage systems like heat exchangers or heat sinks) $[8,9]$. On the other hand, graphene is an excellent solid lubricant and, then, its use as coating for components in moving mechanical systems reduces friction and improves efficiency and durability, which are issues especially important for nano- and micro-scale systems $[10,11,12,13]$. Therefore, the integration of graphene on the surface of $\mathrm{SiC}$ components would improve their performance, provide them with new functionalities and widen the range of potential applications as well. The quality and lateral continuity of the EG obtained by SPS on polycrystalline silicon carbide makes these materials promising for advanced technological applications, in particular, for micro- and nano-electro-mechanical systems or triboelectric devices (nanogenerators, switches, gears, actuators) where large surface friction and conducting channels for charge harvest are required [14]. Moreover, functionalities added by the EG on the SiC substrate, as the hydrophobicity or the enhanced heat dissipation, are of interest for uses such as thermal dissipation or sensing applications $[15,16]$. Although the EG growth on SiC single crystals is a well-established method, the works related with graphene growth on polycrystalline $\mathrm{SiC}$ are actually scarce $[17,18]$.

According to prior results on $\mathrm{EG}$ grown over $\mathrm{SiC}$ single crystals, diverse growth rates and characteristics -in terms of surface morphology, thickness and quality- are reported for different $\mathrm{SiC}$ faces $[19,20,21]$. In general, significantly thicker layers are reported for EG grown over the m-/a- (non-polar) faces and the $\mathrm{C}$-face than over the $\mathrm{Si}$-face; besides, $\mathrm{EG}$ is more stressed for the latter. These differences in the graphene growth rate likely result from an inherent energetic instability of the C-face compared to the Si-face that is a stable lowenergy surface [19]. Furthermore, differences in the surface free energies of the distinct $6 \mathrm{H}-\mathrm{SiC}$ faces have been attributed to downward relaxation of the top layer atoms, caused 
by bond-bending angular forces at the second-layer atoms, strongly affecting $\mathrm{C}$ atoms as compared to Si atoms [22].

The mechanical and electrical properties of polycrystalline materials are not ruled by the weighted bulk properties of the individual crystals but depend notably on the defect density and specific details related to grain boundaries and grain size. Accordingly, to get insight into the intrinsic properties of the material methods averaging over differently orientated domains and domain boundaries are inappropriate and techniques providing local characteristics are required. In particular, the combination of imaging methodologies allowing direct correlation between the different types of grains coexisting in the same sample and their specific properties is of enormous interest. In this work, we investigate EG films developed during SPS on polished surfaces of dense polycrystalline SiC substrates. Owing to the polycrystalline nature of ceramics, the exposed surfaces of the investigated $\mathrm{SiC}$ specimens contain grains randomly oriented, i.e., nonpolar a- and $\mathrm{m}$-planes and polar C- and Si-planes. The present research benefits from the coexistence of such diverse orientations and the imaging mode of the employed techniques to provide a comparative analysis of the diverse EG films simultaneously grown on different $\mathrm{SiC}$ faces developed under exactly the same conditions. This circumstance allows exploring and reliably correlating the nanoscale properties with characteristics typical of few layers of epitaxial graphene as coupling with the substrate, friction attributes or defects induced by strain relief and surface corrugation [23,24,25].

\section{Experimental}

\subsection{Characterization techniques}

Micro-Raman maps were recorded by confocal Raman-atomic force microscopy (model Alpha300AR, WITec GmbH, Germany), using the $532 \mathrm{~nm}$ laser wavelength excitation, and acquisition wavenumber up to $3000 \mathrm{~cm}^{-1}$. All measurements were performed using a $100 \mathrm{x}$ objective, giving, for the employed excitation wavelength, a theoretical lateral resolution of $300 \mathrm{~nm}$ and depth resolution of $500 \mathrm{~nm}$. The integrated intensity (I), peak position (P) and full-width at half maximum (FWHM) of the different observed bands were extracted from 
the corresponding Lorentzian fittings. We note that while G- and 2D-bands peak position and intensity analysis is considered as a standard for the measurements of defect density and graphene thickness in graphene layers grown on flat surfaces, results on rough surfaces like those of the present work should be considered with caution.

Field emission scanning electron microscopy (FESEM, S-4700, Hitachi, Japan) was employed to examine the microstructures of the exposed specimen surfaces before and after the heat treatments. Elemental composition analysis for $\mathrm{C}(\mathrm{K})$ and $\mathrm{Si}(\mathrm{K})$ was obtained from the X-ray energy dispersive spectroscopy analysis system (EDS, Tracor Northern) attached to the FESEM, using the ZAF (atomic number, absorption, fluorescence) correction software and theoretical internal standards.

Scanning force microscopy (SFM) measurements were performed using a commercial head and freeware from Nanotec [26]. Tips of different materials mounted on cantilevers with the appropriate stiffness were employed for contact and dynamic SFM operation: (i) Si tips and low nominal force constant $\left(\mathrm{k}=0.05 \mathrm{~N} \mathrm{~m}^{-1}\right)$ cantilevers for friction force microscopy (FFM) and (ii) conducting $\mathrm{Cr}-\mathrm{Pt}$ coated tips in cantilevers with nominal $\mathrm{k}=3 \mathrm{~N} \mathrm{~m}^{-1}$ and resonance frequency $75 \mathrm{kHz}$ for Kelvin probe force microscopy (KPFM). The former are especially suited for lateral force detection due to a sensitive response to torsion during scanning, while the later exhibit a good electrical conductivity and resistance to wear. In this work, FFM [27] has been used to assess the mechanical differences, whereas KPFM [28] in the lift mode $(30 \mathrm{~nm})$ was used to accurately determine local variations of the surface contact potential difference ensuring no crosstalk with topography. Tip-sample conditions were systematically checked by force versus distances curves. The same tip was used in all the experiments of at least one series. For further details on the SFM operation modes see the available Supporting Information.

Micro-scratch tests (APEX-1L0, Bruker, USA) were done on both the pristine polished SiC and treated surfaces using a diamond micro-tip with a radius of $5 \mu \mathrm{m}$ and a load cell of 10 $\mathrm{N}$. The tests were completed by linearly increasing the tip load from $2 \mathrm{mN}$ to either 10 or $50 \mathrm{mN}$ over a scratch length of $2 \mathrm{~mm}$ at constant speed of $0.025 \mathrm{~mm} \cdot \mathrm{s}^{-1}$. The coefficient of friction (COF) was continuously recorded during the diamond tip sliding. Error in COF values were in the range \pm 0.04 to \pm 0.07 . The minimum load that produced visible surface 
damage or threshold load $\left(\mathrm{F}_{\text {th }}\right)$-optical microscopy observations (10x)- was determined from the corresponding scratch length estimated using digital zoom. At least three scratches per condition were made. Error in threshold load measurements were in the range \pm 0.1 to \pm 0.7 . Besides, surface damage was comparatively analyzed by micro-Raman spectroscopy.

\subsection{Sample preparation}

Commercially available $\alpha$-SiC (Hexoloy S.A., Saint-Gobain) plates with density of $\approx 3.15 \mathrm{~g} \cdot \mathrm{cm}^{-3}$ were used as substrates. The plates were polished to a surface roughness below $0.02 \mu \mathrm{m}$. These specimens were treated at $1600^{\circ} \mathrm{C}$ for $5-15$ min under vacuum conditions (4 Pa) inside the SPS furnace (SPS-510CE; Fuji Electronic Industrial Co., Ltd., Japan) at a heating rate of $\sim 133{ }^{\circ} \mathrm{C} \cdot \mathrm{min}^{-1}$, using special die tools purposely designed to allow current $-\geq 850$ A during final step, depending on die and specimen- flowing through the specimens while exposing part of the polished surface to the surrounding atmosphere. The two alternative assemblies are shown in Figure 1. The graphene growth was analyzed within the ring or the inner loop in the case of the punch-type die or the hole-type die of the corresponding specimen, respectively. Different specimens were prepared for diverse applied pressures (from almost 0 to $100 \mathrm{MPa}$ ), which affected the resistance of the whole SPS system measured during the corresponding heating runs (see below). However, no correlation between the employed type of die and the properties here investigated was found. Therefore, the diverse specimens will be denoted by S_X, where $\mathrm{X}$ is the applied pressure. 


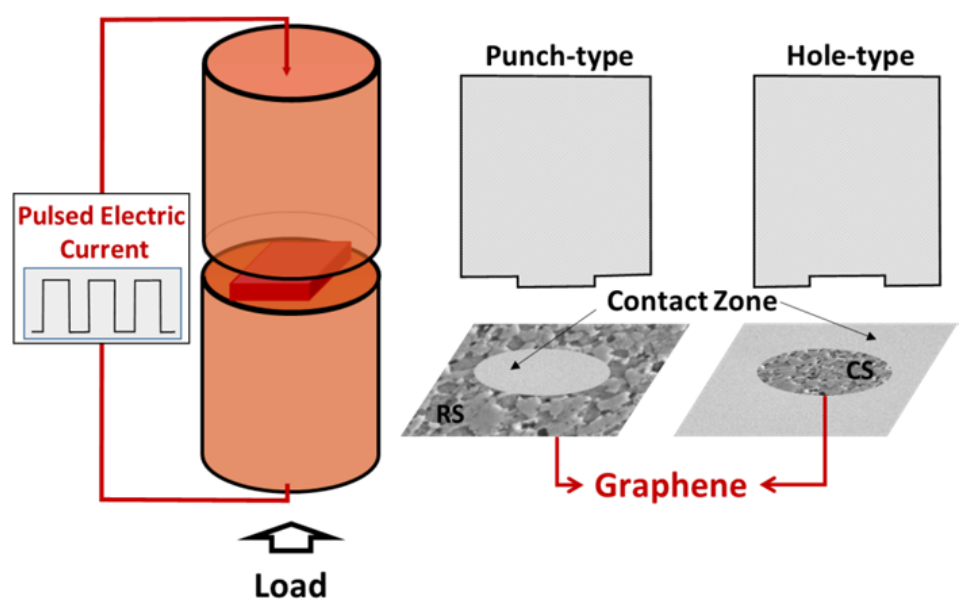

Figure 1. Schematics of the graphite die SPS assemblies: Punch-type and Hole-type. For each case, graphene growth was analyzed at the regions other than the contact zones. Dimensions of the contact zone depended on the sample size and the punch or hole geometries but it was $\sim 50 \mathrm{~mm}^{2}$ for all samples except for S_20 that was of $170 \mathrm{~mm}^{2}$.

\section{Results and discussion}

Conversely to the contrast-free pristine polished $\mathrm{SiC}$, representative FESEM images of heat treated surfaces (Figure 2) confirm the presence of grains with a mean size of $3.4 \mu \mathrm{m}$ (see Figure S1 in the Supporting Information showing size distribution with a full width at half maximum $\mathrm{FWHM} \approx 5 \mu \mathrm{m})$ and a variety of textures and topographic levels. Though this texturing is significantly sharper for the specimen grown at the minimum load pressure (S_0) than for the other specimens, common topographic characteristics in all investigated samples serve to identify the grain orientations and their corresponding properties.

Raman spectroscopy for the pristine surface only exhibits the two main bands of $6 \mathrm{H}-\mathrm{SiC}$ polytype, at $789 \mathrm{~cm}^{-1} \mathrm{FTO}(\mathrm{E})$ and at $966 \mathrm{~cm}^{-1} \mathrm{FLO}(\mathrm{A} 1)$ [29], with $\mathrm{I}_{\mathrm{SiC}}(\mathrm{FTO}) / \mathrm{I}_{\mathrm{SiC}}(\mathrm{FLO})$ ratios chiefly in the range 1-2 as estimated from scan maps over areas as large as $30 \mu \mathrm{m} \mathrm{x}$ $30 \mu \mathrm{m}$ (Figure S2 and Figure S3 in the Supporting Information). However, the presence of intense graphene $\mathrm{D}, \mathrm{G}$ and 2D bands for heat treated substrates clearly indicates the growth of graphene layers induced by the raise of specimen's temperature, most probably governed 
by the local joule heating of the sample. The Raman spectra-averaged over $15 \mu \mathrm{m}$ x $15 \mu \mathrm{m}$ areas- for the specimen with the highest graphene signal (S_0) and the pristine SiC sample are compared in Figure 2c. Besides, significant differences in the intensity of the graphene bands were detected among treated specimens; in this way, the integrated intensity ratio for graphene and silicon carbide peaks, $\mathrm{I}_{\mathrm{G}} / \mathrm{I}_{\mathrm{SiCT}}$ (where $\mathrm{I}_{\mathrm{SiCT}}$ represents the sum of the integrated intensity of the two SiC bands), varies between 2 and 12. Interestingly, $\mathrm{I}_{\mathrm{G}} / \mathrm{I}_{\mathrm{SiCT}}$ is directly correlated with the initial stage electrical resistance of the SPS assembly (Figure 2d), which implies differences in the electric field and is found to inversely depend on the applied pressure, from $7.9 \mathrm{~m} \Omega$ for the lowest pressure (S_0) to $5.7 \mathrm{~m} \Omega$ for $100 \mathrm{MPa}\left(\mathrm{S} \_100\right)$. The joint effect of pressure, rapid heating and activating action of the electric field seem to play an important role in the graphene formation [30].

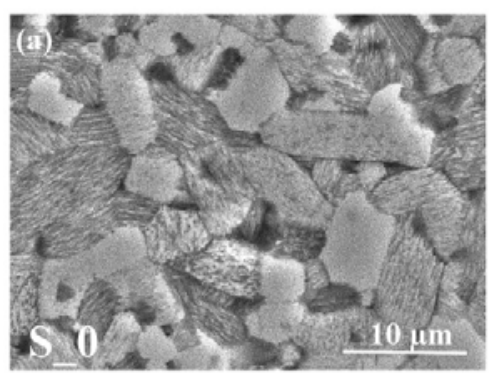

(c)

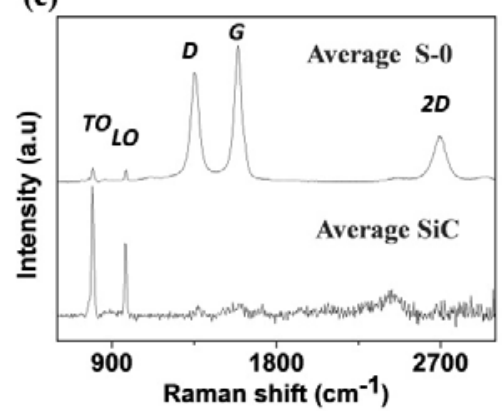

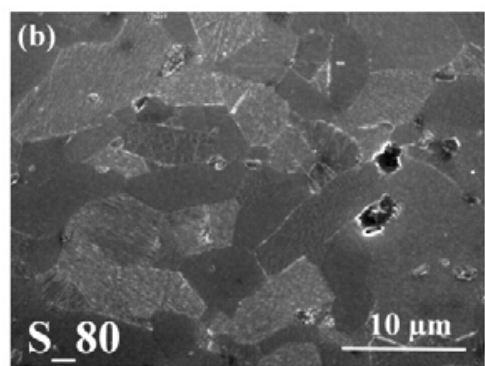

(d)

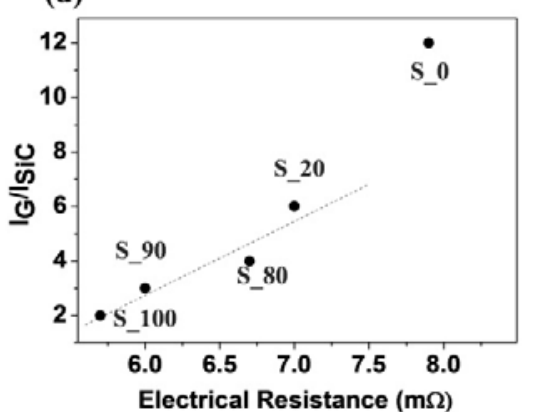

Figure 2. FESEM micrographs of representative samples after the heat treatment for different applied pressure: (a) lowest applied pressure (S_0), (b) $80 \mathrm{MPa}$ (S_80). (c) Average spectra (over $15 \mu \mathrm{m}$ x $15 \mu \mathrm{m}$ ) for the pristine SiC and S_0. For monolithic SiC background was removed to facilitate comparison. (d) Intensity ratio $\left(\mathrm{I}_{\mathrm{G}} / \mathrm{I}_{\mathrm{SiCT}}\right)$ between the area of the G-band of graphene and the total area associated to the two main $\mathrm{SiC}$ bands (at $789 \mathrm{~cm}^{-1}$ and $966 \mathrm{~cm}^{-1}$ ) plotted as a function of the electrical resistance of the whole SPS assembly at the initial stage. 
The diverse grains within each polycrystalline specimen can be distinguished by the Raman intensity ratio between FTO and FLO bands (see Figure S2 in the Supporting Information), which may well be linked to differences in doping, defects and $\mathrm{C} / \mathrm{Si}$ ratio [17,31,32]. Due to the distinct graphene growth rate for different $\mathrm{SiC}$ faces $[9,11,16,17]$, the grown $\mathrm{EG}$ is expected to significantly vary along the surface on the polycrystalline material, in which all planes are subjected to the same temperature and atmosphere, particularly the graphene layer would be thicker on C-faces than on Si-faces [33,34]. The mentioned contrast observed in the FESEM images is then associated to the diverse surface receding that results in an increased surface average roughness $\left(\mathrm{R}_{\mathrm{a}}\right)$ over areas at the millimeter scale and arises from the dependence of $\mathrm{Si}$ sublimation and graphene growth rates on surface orientation. In fact, EDS analysis of less receded grains gives ratios of $66 \mathrm{C} / 34 \mathrm{Si}$ (at. \%) whereas for highly receded grains the relative amount of $\mathrm{C}$ is estimated as large as $75 \mathrm{C} / 25$ Si (at.\%.). The thoroughgoing combined optical, topographical and Raman microscopy analyzed here in comparison to reported results for EG on $\mathrm{SiC}$ single crystals serves to identify these grains as appertaining to Si-face and C-face families, respectively, thus allowing an adequate classification of the grain orientations encountered in our samples.

The Raman results for the three specimens with higher graphene content (S_80, S_20 and S_0) are summarized in the top part of Table 1. Despite $\mathrm{I}_{\mathrm{SiC}}(\mathrm{FTO}) / \mathrm{I}_{\mathrm{SiC}}(\mathrm{FLO})$ lies in a similar range than for the pristine case, the $\mathrm{I}_{2 \mathrm{D}} / \mathrm{I}_{\mathrm{G}}$ ratios extracted from the average spectra (containing grains with different FESEM contrast) are very similar for the three samples, indicating similar quality of their graphene films. However, a direct relation between $\mathrm{I}_{\mathrm{D}} / \mathrm{I}_{\mathrm{G}}$ in Table 1 with the electrical resistance in Figure $2 d$ indicates a certain increase of defects with applied current. Moreover, the increase in $\mathrm{I}_{\mathrm{D}} / \mathrm{I}_{\mathrm{G}}$ ratio with $\mathrm{I}_{\mathrm{G}} / \mathrm{I}_{\mathrm{SiCT}}$ points to a rise of defects as graphene growth progresses. A blue-shift of the $\mathrm{G}$-band $\left(\mathrm{P}(\mathrm{G})=1605 \mathrm{~cm}^{-1}\right)$ is also perceived in the average spectra of all samples as compared to free-standing multilayered graphene and graphite, for which $\mathrm{P}(\mathrm{G}) \sim 1587 \mathrm{~cm}^{-1}$. This blue-shift can be attributed to the compressive strain [35,36] in the graphene film after cooling that is induced by the much higher thermal expansion coefficient of the $\mathrm{SiC}$ substrate $\left(\sim 4.9 \times 10^{-6} \mathrm{~K}^{-1}\right.$ from room temperature to $\left.800^{\circ} \mathrm{C}\right)$ [37] compared to that of graphene (< $1 \times 10^{-6} \mathrm{~K}^{-1}$ for the same temperature range) [38]. 


\begin{tabular}{|c|c|c|c|c|c|c|c|}
\hline $\begin{array}{l}\text { Average } \\
\text { spectrum }\end{array}$ & $\begin{array}{c}\text { D } \\
\left(\mathrm{cm}^{-1}\right)\end{array}$ & $\begin{array}{c}\mathbf{G} \\
\left(\mathrm{cm}^{-1}\right)\end{array}$ & $\begin{array}{c}2 \mathbf{D} \\
\left(\mathrm{cm}^{-1}\right)\end{array}$ & $\mathbf{I}_{\mathbf{D}} / \mathbf{I}_{\mathbf{G}}$ & $\mathbf{I}_{2 \mathrm{D}} / \mathbf{I}_{\mathbf{G}}$ & $\begin{array}{l}\mathbf{I}_{\mathrm{SiC}}(\mathrm{TO}) \\
/ \mathbf{I}_{\mathrm{SiC}}(\mathrm{LO})\end{array}$ & $\mathbf{I}_{\mathrm{G}} / \mathbf{I}_{\mathrm{SiCT}}$ \\
\hline S_80 & 1375 & 1605 & 2730 & 0.5 & 0.4 & 2.2 & 3 \\
\hline S_20 & 1367 & 1605 & 2719 & 0.7 & 0.5 & 2.2 & 6 \\
\hline S_0 & 1373 & 1605 & 2728 & 0.9 & 0.5 & 0.8 & 12 \\
\hline $\begin{array}{c}\text { Single grain } \\
\text { spectrum }\left(\mathrm{S} \_0\right)\end{array}$ & & & & & & & \\
\hline i) C-face* & $\begin{array}{c}1348 \\
\pm 4\end{array}$ & $\begin{array}{c}1582 \\
\pm 6\end{array}$ & $\begin{array}{c}2685 \\
\pm 7\end{array}$ & $\begin{array}{c}1.0 \\
\pm 0.1\end{array}$ & $\begin{array}{c}0.60 \\
\pm 0.20\end{array}$ & --- & \\
\hline ii) $\mathrm{m} / \mathrm{a}-$ faces* & $\begin{array}{c}1361.3 \\
\pm 0.6\end{array}$ & $\begin{array}{c}1597 \\
\pm 2\end{array}$ & $\begin{array}{c}2706 \\
\pm 4\end{array}$ & $\begin{array}{c}0.9 \\
\pm 0.1\end{array}$ & $\begin{array}{c}0.58 \\
\pm 0.03\end{array}$ & $1.2-1.9$ & $\begin{array}{l}18 \\
\pm 6\end{array}$ \\
\hline iii) Si-face* & $\begin{array}{c}1369 \\
\pm 6\end{array}$ & $\begin{array}{c}1603 \\
\pm 3\end{array}$ & $\begin{array}{c}2726 \\
\pm 9\end{array}$ & $\begin{array}{c}0.6 \\
\pm 0.2\end{array}$ & $\begin{array}{c}0.30 \\
\pm 0.10\end{array}$ & $1.0-5.4$ & $1.2 \pm 0.7$ \\
\hline
\end{tabular}

Table 1. Top: Positions of the D, G and 2D bands, and integrated intensity ratios between the indicated Raman bands for the average spectra $(15 \mu \mathrm{m} \times 15 \mu \mathrm{m})$ of samples S_80, S_20 and S_0. Bottom: Same for spectra acquired on single grains $\left(^{*}\right)$ of the S_0 sample. $\mathrm{I}_{\mathrm{SiCT}}=$ $\mathrm{I}_{\mathrm{SiC}}(\mathrm{TO})+\mathrm{I}_{\mathrm{SiC}}(\mathrm{LO})$.

Similarly to what is observed in FESEM, in contrast to the smooth surface of the pristine $\mathrm{SiC}$, the optical micrographs of the treated specimens show large contrast between grains (Figure S4 in the Supporting Information). In such a way, data obtained for the same surface region (Figure 3) allow correlating morphological details from optical (Figure 3a) and SFM imaging (Figure 3b) with local composition variations inferred from Raman maps (Figure 3c) generated by filtering intensity of the G-band (green) and FTO band (blue) of $6 \mathrm{H}-\mathrm{SiC}$. In fact, the optical contrast is due to light attenuation produced by cumulative 
graphene layers over the substrate [39] which progressively reduce the intensity of $\mathrm{SiC}$ bands in the spectra as film thickness increases, thus supporting that blue regions are grains with lower graphene content.

It is noteworthy to carefully examine the differences in the Raman spectra acquired at single grains. Though the classification presented in the lower part of Table 1 pertains to S_0 specimen, the conclusions can be fully extended to the rest. Grains with different contrast in optical micrographs have been categorized in three groups according to the Raman intensity of their $\mathrm{SiC}$ bands: i) dark grains with no detectable $\mathrm{SiC}$ bands, ii) grayish grains showing low intensity $\mathrm{SiC}$ bands and iii) light grains with the strongest signal for $\mathrm{SiC}$. These groups are fount to correspond to the SiC-plane families, in particular, C-face, non-polar faces (m- and a-) and Si-face, respectively. Thus, a low graphene content $\left(\mathrm{I}_{\mathrm{G}} / \mathrm{I}_{\mathrm{SiCT}}\right.$ $\sim$ 1.2) and faint surface receding (lighter color in Figure 3a) are consistent with Si-face grains showing strong blue shift of the G-band and lower $\mathrm{I}_{\mathrm{D}} / \mathrm{I}_{\mathrm{G}}$ and $\mathrm{I}_{2 \mathrm{D}} / \mathrm{I}_{\mathrm{G}}$ ratios; the grains of non-polar faces show significantly higher amount of graphene $\left(\mathrm{I}_{\mathrm{G}} / \mathrm{I}_{\mathrm{SiCT}}=18\right)$ but more defective as pointed out by a higher $\mathrm{I}_{\mathrm{D}} / \mathrm{I}_{\mathrm{G}}$ and certain blue shift; for the $\mathrm{C}$-face grains only graphene peaks are detected (Figure 3e) and negligible G-band shift is observed. For more details on the blue-shifts of the differently oriented grains see Figure S5 in the Supporting Information. Summing up, the parallel increase of $\mathrm{I}_{\mathrm{D}} / \mathrm{I}_{\mathrm{G}}$ and $\mathrm{I}_{\mathrm{G}} / \mathrm{I}_{\mathrm{SiCT}}$ for the Raman spectra of C-face grains matches with the coherent contribution of several EG layers on these grains, as compared to thinner films on Si-face, as the growth progresses. Moreover, from the SFM topographic image of Figure $3 b$ and the corresponding line profile (Figure 3d), it can be seen that the $\mathrm{C}$-face grains show a significantly large roughness, whereas $\mathrm{Si}$-face grains are the smoothest and have an average surface level $\sim 15-20 \mathrm{~nm}$ above the others (Cand $\mathrm{m} / \mathrm{-a}-)$ due to a lower surface recoil. 

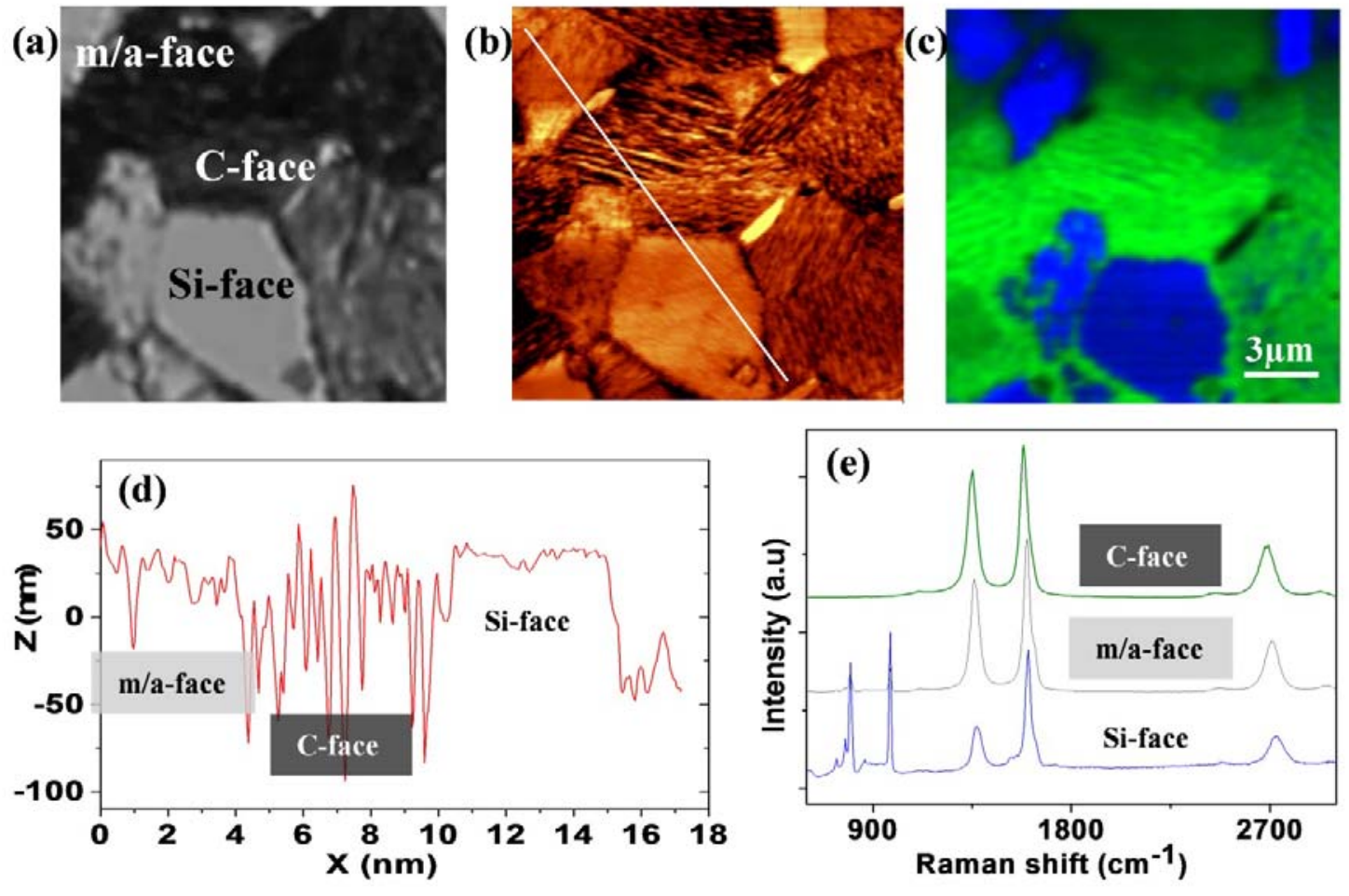

Figure 3. (a) Optical image of the S_0 specimen, (b) SFM topography of the same area, (c) false color Raman image generated by merging intensity maps of the G-band (green) and the FTO band (blue), (d) profile along the line marked in (b), and (e) Raman spectra at the different grains indicated in (a).

Depth profiling Raman data obtained across adjacent grains of different orientations is displayed in Figure 4. The in-depth intensity of TO (Figure 4a) and G-band (Figure 4b) are in agreement with the above mentioned grain classification, namely, distinct receding surface levels, larger for $\mathrm{C}$-face than for $\mathrm{m} / \mathrm{a}$ - and $\mathrm{Si}$ - faces and higher $\mathrm{G}$-band intensity for the C-face. Notably, G- and 2D-bands peak position and FWHM for the m/a-, C- and Siface grains can be used to estimate graphene film thickness by comparing with measurements reported in literature regarding the peak characteristics of exfoliated multilayer and epitaxial grown graphene. FWHM values for the 2D peak (Figure 4-c.4) are in the range of $\sim 55 \mathrm{~cm}^{-1}$ for $\mathrm{Si}$-face and $\sim 62 \mathrm{~cm}^{-1}$ for $\mathrm{C}$-face; whereas $\mathrm{P}(2 \mathrm{D})$ values are $\sim 2725 \mathrm{~cm}^{-1}$ and $\sim 2708 \mathrm{~cm}^{-1}$, respectively. These values are similar to those reported for 
EG grown on $4 \mathrm{H}-$ and $6 \mathrm{H}-\mathrm{SiC}$ single crystals $[40,41,42]$, for $\sim 10$ layers graphene (MLG) on C-faces and bilayer graphene (BLG) on Si-faces.

(a)

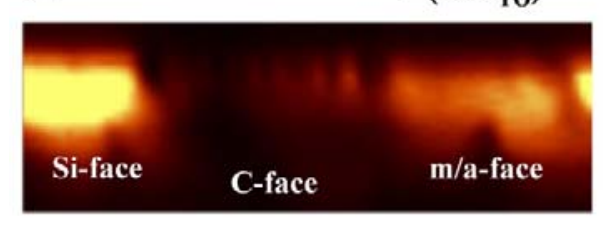

(c)
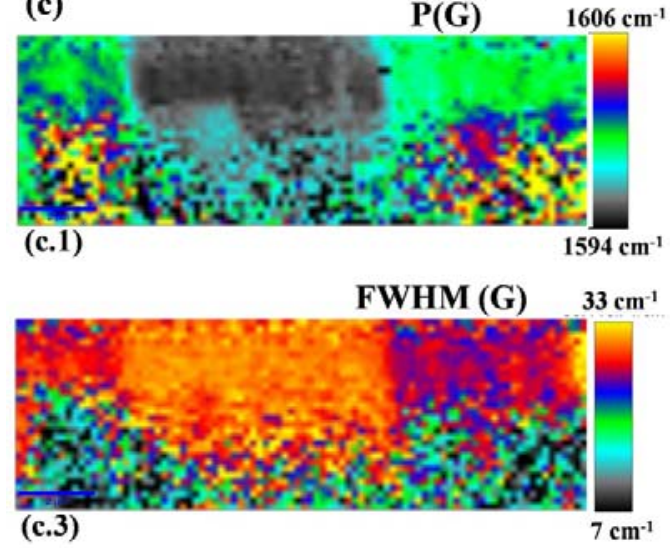

(b)
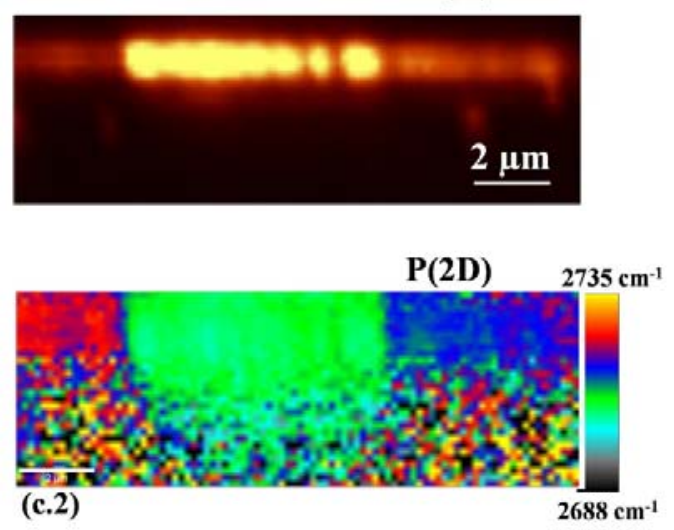

FWHM (2D) $66 \mathrm{~cm}^{-1}$

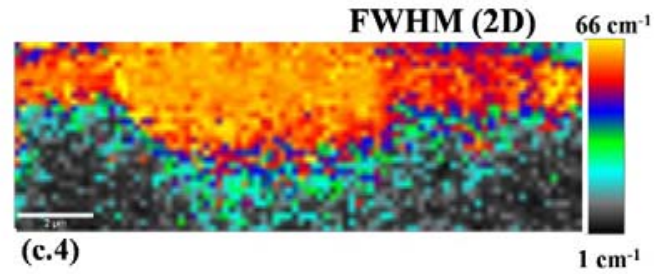

Figure 4. Depth profiling Raman maps along a line crossing different $\mathrm{SiC}$ grains (m/a, C and $\mathrm{Si}$ faces) for sample S_20: (a) SiC TO intensity, (b) G-band intensity, (c) peak positions of G-band (c.1) and 2D-band (c.2) and their corresponding FWHM (c.3, c.4). The total $\mathrm{Z}$ travel equals $5 \mu \mathrm{m}$ in all cases.

The averaged surface roughness for each family of grains has been determined from root mean square (rms) analysis of the S_80 and S_20 samples obtained by averaging at least 20 profiles taken on different grains and different SFM images (see Figure S6 in the Supporting Information). A typical example is shown in Figure 5, where three types of grains can be clearly distinguished in the topographic image (Figure 5a) with fine morphological details enlarged in the derivative image (Figure 5b). Grains of the $\mathrm{m} / \mathrm{a}$ family exhibit an intermediate corrugation with $\mathrm{rms} \approx 3-4 \mathrm{~nm}$ (see several of those grains coexisting in Figure $5 \mathrm{c}$ ) while a large difference is observed among those of $\mathrm{C}$ - face $(\mathrm{rms} \approx$ 
$8 \mathrm{~nm})$ and the Si-face ( $\mathrm{rms} \approx 2 \mathrm{~nm})$ types. This fact is due to a quite homogeneously stepped surface of the Si-face (Figure 5d) versus the faceted appearance of the C-face (Figure 5e). The Si-face grains are covered by regular arrays of relatively long terraces typically extending few $\mu \mathrm{m}$ and only $\sim 50 \mathrm{~nm}$ wide (see also Figure $5 \mathrm{~b}$ ). This width is determined by the particular misorientation of the grain surface with respect to the crystallographic (0001) plane. The steps present heights ranging from $1.5 \mathrm{~nm}$ (dimension of the $\mathrm{SiC}$ unit cell in the direction perpendicular to the surface plane) up to $5 \mathrm{~nm}$ with no observable step bunching (see Figure S7 in the Supporting Information). In this type of surface, the formation of an interface layer is known to act as a template for the EG growth in a nearly layer-by-layer fashion and to be responsible of a well-defined azimuthal orientation of the carbonaceous layer $[43,44,45,46]$.
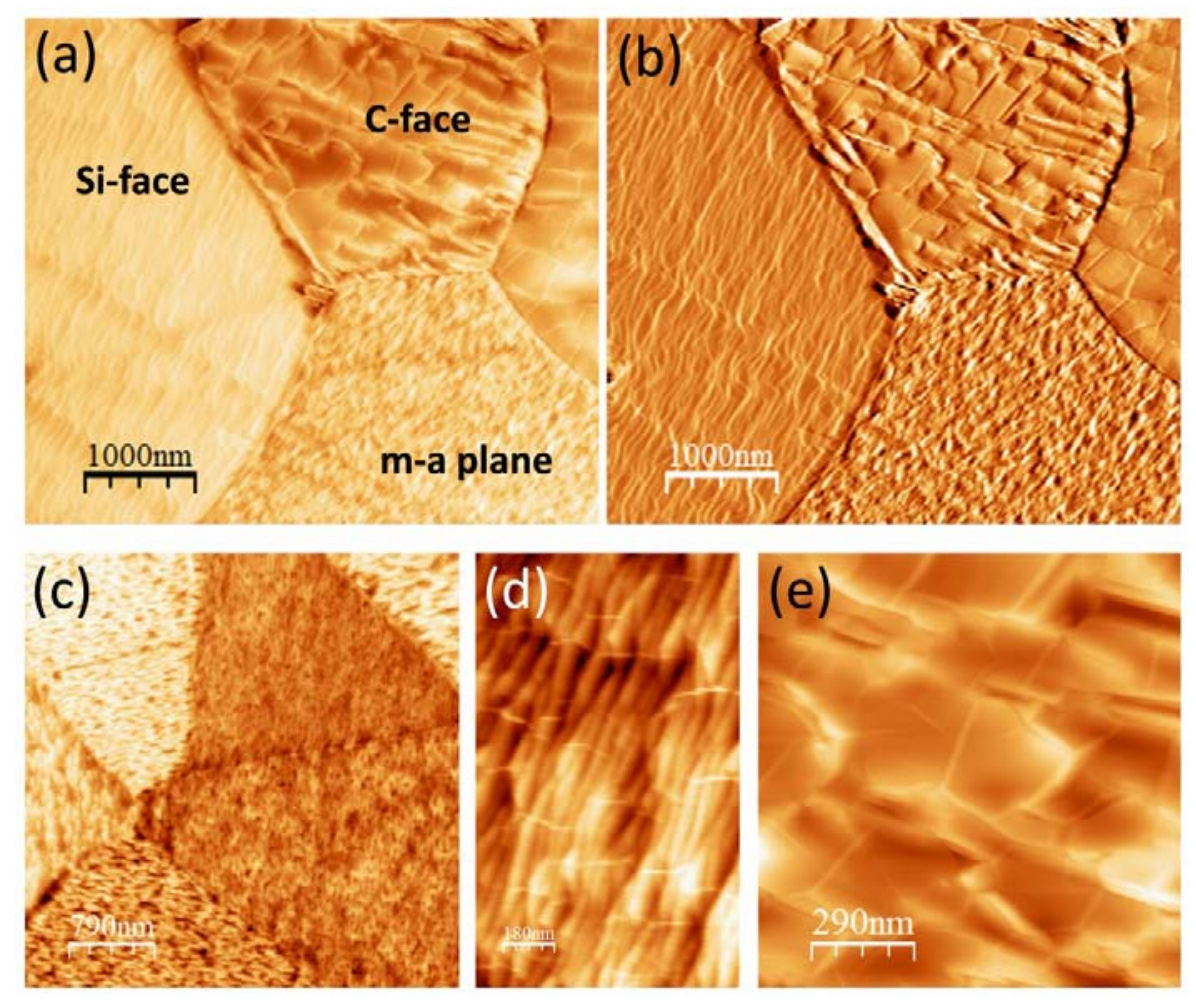

Figure 5. Topographic SFM images of : (a) grains in S_80 with three different orientations as indicated in the respective labels, $\mathrm{Z}_{\mathrm{t}}=25 \mathrm{~nm}$ (b) derivative image of (a), (c) diverse grains with non-polar orientations in $S_{-} 20, Z_{t}=15 \mathrm{~nm}$ (d) and (e) are magnified areas of the $\mathrm{Si}$-face and $\mathrm{C}$-face grains in (a), respectively. $Z_{t}$ indicates the total height scale for each image. 
In both polar $\mathrm{C}$ - and $\mathrm{Si}$-face oriented grains, a mesh of lines can be seen dividing the surface into trapezoidal domains of 200-300 $\mathrm{nm}$ (Figures 5d and 5e) consisting of a network of partial tube-like structures (ripples) not present in the non-polar planes that otherwise present a homogeneous amorphous-like appearance (Figure $5 \mathrm{c}$ ). These ripples seem to have great influence on the graphene properties $[25,47,48,49]$. They form during the cooling step of EG and arise from strain release at the boundary between neighboring graphene domains due to the different thermal expansion coefficients between graphene and the $\mathrm{SiC}$ basal plane [42], as stated above from Raman results. The network is particularly notable in the $\mathrm{C}$-face (Figure 5e) and significantly reduces the magnitude of inplane stresses generated by defects [50,51]. As a consequence, these grains display an overall roughened surface but contain atomically flat regions as large as $\sim 9 \times 10^{3} \mathrm{~nm}^{2}$ between ripples. On the other hand, the larger $\mathrm{I}_{\mathrm{D}} / \mathrm{I}_{\mathrm{G}}$ (Table 1) and insignificant shift of the $\mathrm{G}$ band in the $\mathrm{C}$-face, which reflect a larger defects density but more relaxed graphene, may indicate either more or larger ripples in these grains, lack of thickness uniformity as well as single or extended vacancies but also arise from rotational disorder. A discussion on the role of distinct defects on graphene friction is presented in the Supporting Information accompanied by analysis (Table S1) of the double resonance band (D') associated to defects located close to $\mathrm{G}$ band at $\sim 1620 \mathrm{~cm}^{-1}$. Interestingly, despite the considerably different graphene content, the ripple network crosses the boundary between adjacent grains of both orientations (Figure 6a) suggesting that a carpet-like uniform graphene film covers them without disruption of the carbonaceous layer [52]. The ripples are relatively wide $(\sim 20 \mathrm{~nm})$ and $\sim 2-4 \mathrm{~nm}$ high (Figure $6 \mathrm{~d}$ ) with no particular dependence on grain orientation. The relatively thick MLG grown on the C-face does not pile in the AB Bernal stacked manner as in the Si-face. Instead, it presents a high azimuthal disorder as a consequence of the weak interaction with the substrate that confers to the multilayer system properties close to the individual single-layer [53,54,55]. All these circumstances have effects in the morphology of the grown graphene and are discussed below. 

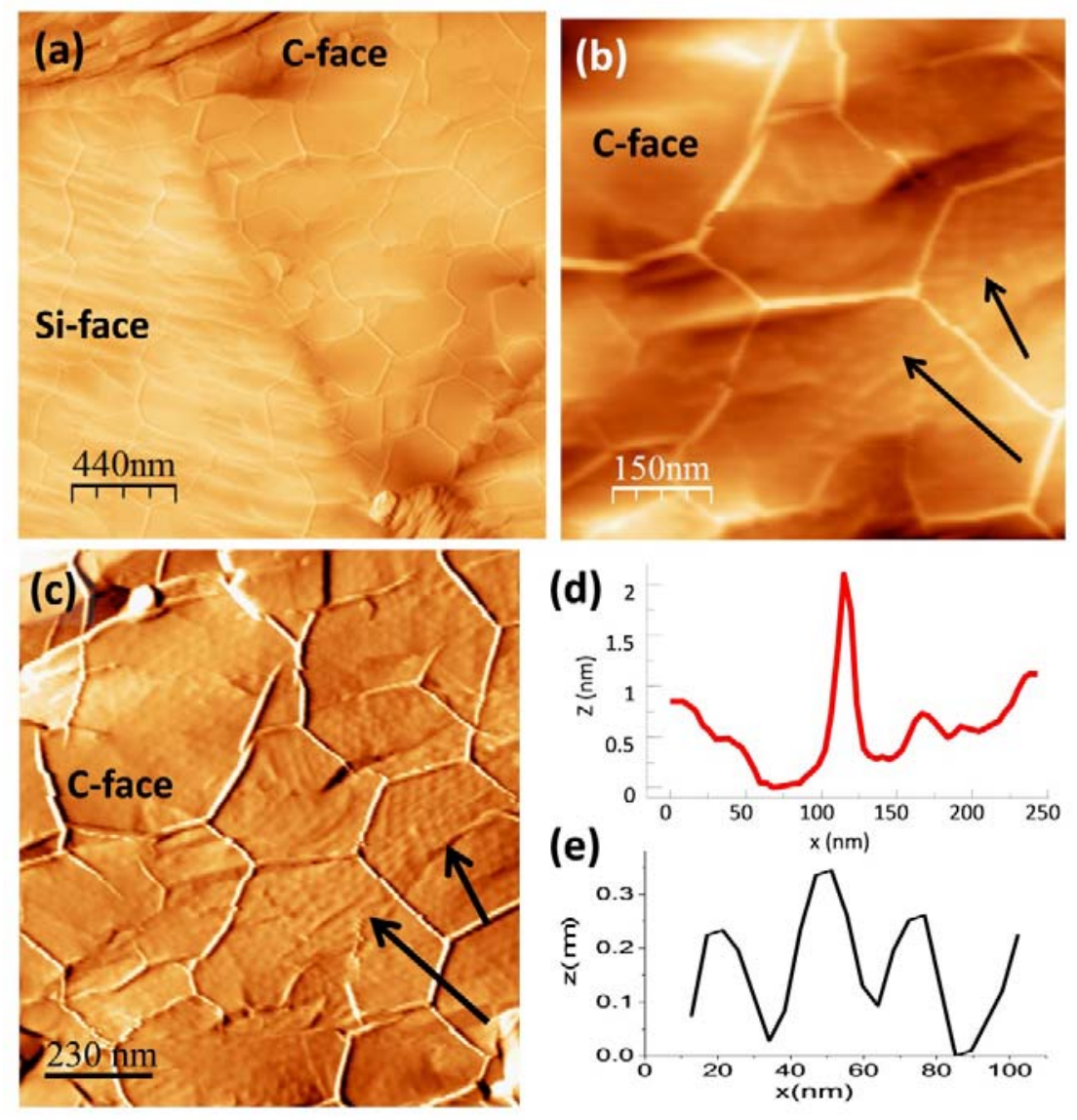

Figure 6. (a) Topographic SFM image containing the boundary between Si-face and C-face grains $(Z=50 \mathrm{~nm})$, (b) topography of a magnified area on the $C$-face grain. To amplify morphological details a derived image is shown in (c). Black arrows in (b) and (c) indicate topographic fringes and deformed structures. Line profiles across a typical ripple in and a wrinkled region seen in (b) are presented in (d) and (e), respectively.

As it would occur in suspended graphene, remaining strain in weakly bounded sheets confined by ripples generates a series of crumpled features in the C-face grains (black arrows in Figure 6b). Any compression or shear held at the graphene domain boundaries may originate deformations along different directions leading to linear fringes and varying super-lattice structures [56] in the different domains as notably amplified in the derivative topography (Figure 6c). The number and size of these strain-induced structures increase with that of the bounded area and number of stacked layers. Within a continuum theory, the 
striation height reached before fracture depends on the Poisson's ratio and simultaneous compression and shear [57]. In the present case, though the coexistence of diverse corrugated structures in the same region does not permit a unique shear strain determination, their low height (Figure 6e) points to a fairly relaxed graphene multilayer. This result is in agreement with the Raman data in Table 1 and Figure 4 where no blue-shift of the G-band is observed for the EG on C-face. In summary, after graphene growth and due to compression during cooling, the graphene is buckled, producing a network of ripples such as that shown in Figure 5 and Figure 6 for both C-face and Si-face grains. In addition, the local incidence of both compression and shear leads to the formation of striations or ridges diagonal to the graphene sheet enclosed by the network, visible for the $\mathrm{C}$-face. The diverse distorted patterns (mostly deformed hexagonal arrays) have a relatively large periodicity of $\sim 22-26 \mathrm{~nm}$ (Figure 6e) and are likely associated to deformations of the top few graphene layers decoupled from the $\mathrm{SiC}$ interface [56].

The existence of the described continuous carpet-like film offers the advantageous benefit of allowing a full exploration at different scales of the mechanical properties (e.g. nanoscale friction and macroscopic wear) of the graphene generated on the distinct $\mathrm{SiC}$ orientations. We first note that the magnitude of the surface friction can be influenced by diverse factors as non-homogeneous graphene thickness and differences in coupling with the substrate but also may arise from a non-uniform strain in the respective layers and, in particular, puckering and out-of-plane floppiness occurring during sliding [58,59]. In the presence of rotated graphene domains, the later would lead to anisotropic friction [60] i.e., a friction dependence on the graphene orientation respect to the sliding direction. In reference to thickness, it has been reported that the frictional force decreases with increasing number of graphene layers, being reduced by a factor of two from the bilayer to the single layer in the case of epitaxial graphene [12] and saturating for about 4-5 atomic FGL transferred to $\mathrm{SiO}_{2}[61]$. The generality of such results for $2 \mathrm{D}$ materials $[58,62]$ seems to indicate that this can be considered as a characteristic of friction at the nanoscale for weakly bound materials. In the present case, the Raman results indicate the formation of MLG on C-faces whereas BLG grows on Si-faces (see Raman discussion), therefore, friction differences arising from thickness are not expected for the same grain though they may differ from grain to grain even for the same orientation family. 

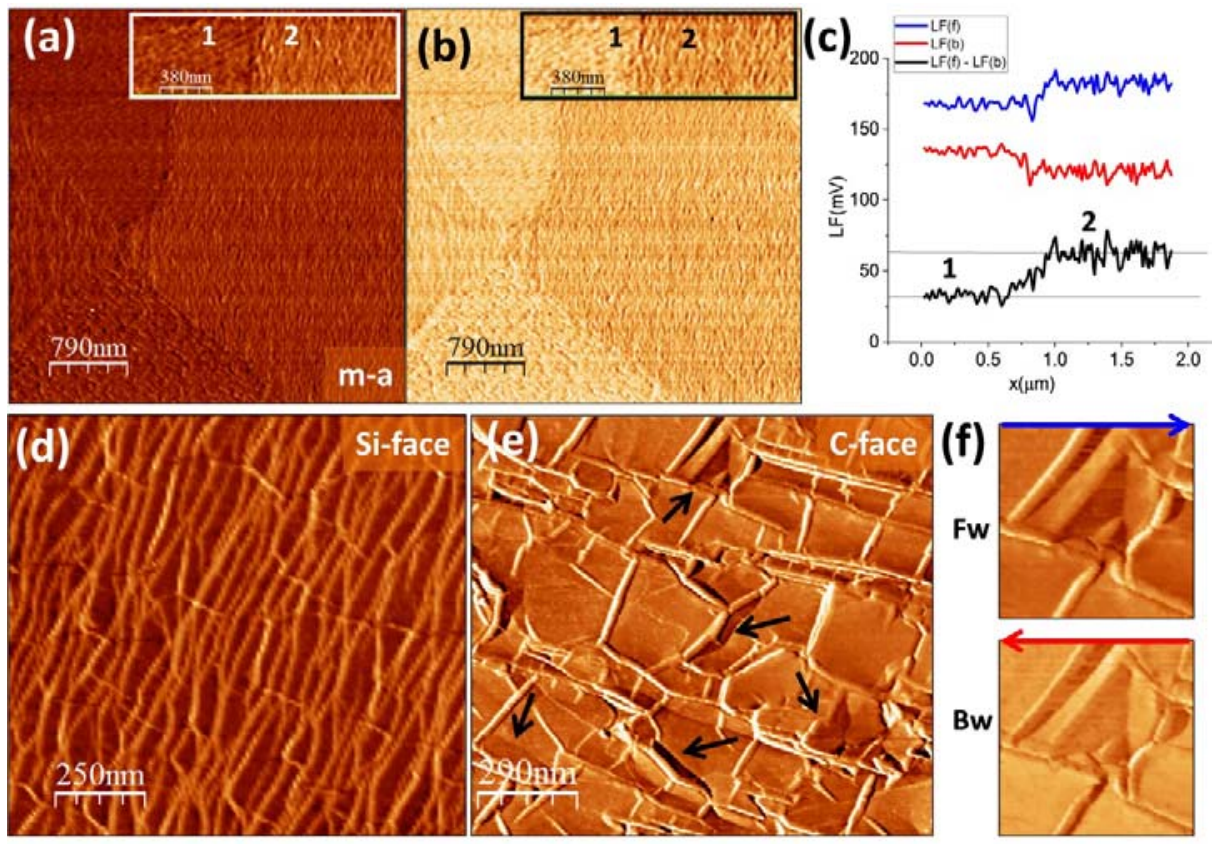

Figure 7. Lateral force (LF) data for the three different families of SiC grains. Forward (a) and backwards (b) images of four meeting grains of m/a- type (same area as Figure 5c), insets in (a) and (b) are magnified regions used to estimate friction data in (c): mean LF profiles (blue/red for forward/backwards) of each region and calculated friction loop height (black) for grains labeled (1) and (2). Only the forward image is shown for Si-face (d) while for the $\mathrm{C}$-face, the complete forward image (e) as well as forward (Fw) and backwards (Bw) magnifications (f) are shown.

Figures $7 \mathrm{a}$ and $7 \mathrm{~b}$ correspond to the forward and backwards lateral force images of the surface area shown in Figure $5 \mathrm{c}$ that contains different grains with $\mathrm{m} / \mathrm{a}$ - orientation or nearby. Highly homogeneous friction is measured on each particular grain, as expected from a uniform graphene thickness. Nevertheless, for m/a- grains exhibiting an oriented texture perpendicular to the sliding direction (2) the friction loop (Figure 7c) opens as to increase the friction twice with respect to those with parallel texture (1). This result is evidence of the role of the sliding direction against or along nanostructured groove channel textures that are relevant for nano- and micro-mechanical devices. In the case of Si-face grains, a homogeneous friction is observed as well (Figure 7d) despite the ripples network, 
pointing to a regular graphene relaxation achieved by the high density of surface steps. However, for the C-face (Figure 7e), a non-uniform lateral force signal close to the ripples is observed in the form of patches (indicated by black arrows). This effect can be due to differences in the friction magnitude due, for example, to local variations in thickness [12] (see Figure S8 in Supporting Information) but is discarded in this particular case because no inverted contrast with reversed scan direction is observed (Figure 7f). This effect, however, turns out to be a friction anisotropy resulting from anisotropic puckering under sliding due to different relative rotation of the graphene domains in the C-face grains [59]. In all cases, and contrary to what has been reported for weakly attached FLG in other SiC materials [30], no damage occurs during continuous SFM sweeping, indicating a certain robustness (see below) and corroborating the lateral continuity of the carpet-like grown EG.

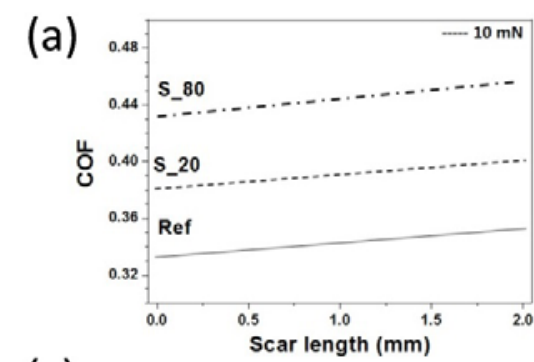

(c)

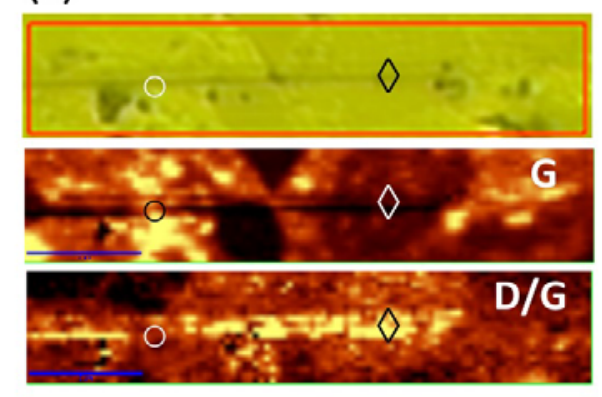

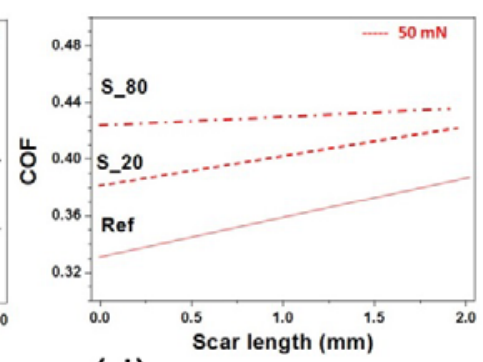

(d)

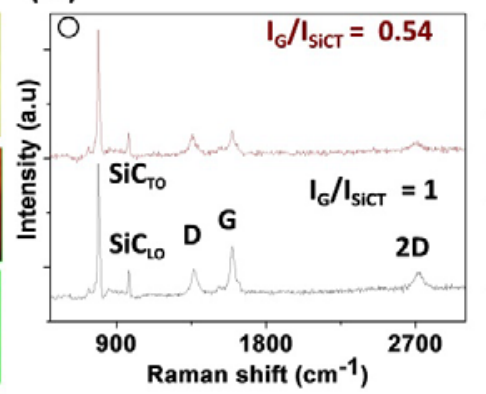

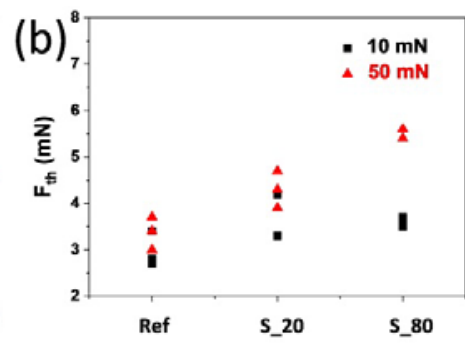

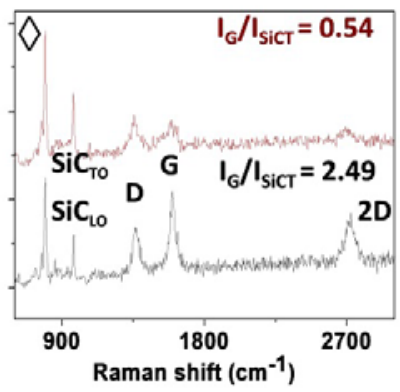

Figure 8. Micro-scratch tests on pristine SiC (Ref) and S_80 and S_20 samples: (a) Average coefficient of friction (COF) as a function of the scratch length for end loads $10 \mathrm{mN}$ and $50 \mathrm{mN}$ (data normalized at the first scar point). Associated errors: \pm 0.05 (Ref), \pm $0.06\left(\mathrm{~S} \_20\right), \pm 0.07\left(\mathrm{~S} \_80\right)$ at $10 \mathrm{mN}$ and \pm 0.05 (Ref), \pm 0.04 (S_20), \pm 0.05 (S_80) at 50 $\mathrm{mN}$, (b) threshold load $\left(\mathrm{F}_{\text {th }}\right)$ at which surface damage is observable by optical microscopy. Associated errors: \pm 0.4 (Ref), \pm 0.7 (S_20), \pm 0.1 (S_80) at $10 \mathrm{mN}$ and \pm 0.4 (Ref), \pm 0.4 (S_20), $\pm 0.2($ S_80) at $50 \mathrm{mN}$. Different points belong to different sample locations, and (c) Optical and Raman images for S_20 constructed by filtering the intensity of the G and 
D/G bands. (d) Raman spectra in Si-face ( $\odot$ ) and m/a-plane $(\diamond)$ along the scar (top) and out of it(bottom).

Further insight on the tribological characteristics of the EG films has been obtained from micro-scratch tests for increasing loads. As seen in Figure 8a, all samples present the typical continuous increase in COF attributed to increasing plowing and contact area with normal load. At this point it is worth noting that the lateral dimension of the produced scar is $\approx 0.25 \mu \mathrm{m}$ (see Figure S9 in the Supporting Information). In such a way, mean COF values for the three samples (Ref $<$ S_20 $<$ S_80, differing in $~ 5 \%$ ) should not be interpreted in terms of the averaged roughness $R_{a}$ estimated over areas at the millimeter scale $\left(\approx 18.5 \mathrm{~nm}\right.$ for $\mathrm{S} \_20$ and $\approx 13.2 \mathrm{~nm}$ for $\mathrm{S} \_80$ and $\approx 9.8 \mathrm{~nm}$ for Ref) that results from the distinct surface levels of more or less receded grains after EG growth (see Figure 2) but explained in terms of the individual grains forming each surface as well as depending on the graphene content. On the one hand, graphene smooths out the respective pristine grains $(\mathrm{rms} \approx 2 \mathrm{~nm}$ for $\mathrm{Si}$-face, $\approx 3-4 \mathrm{~nm}$ for $\mathrm{m} / \mathrm{a}$ - and $\approx 8 \mathrm{~nm}$ for $\mathrm{C}$-face, e.g. Figure 5 and Figure S7) and, on the other hand, S_20 has a larger graphene content than S_80 (Table 1). We also note that during the tests, the tip load is increasing linearly at constant speed (see Experimental), i.e., a given load value is reached earlier in the $50 \mathrm{mN}$ scratch, justifying the stepper increase of these curves in the case of Ref and S_20 respect to the $10 \mathrm{mN}$ curves. However, S_80 does show a nearly constant value for the high end load case which might arise from a little dependence of contact area with load that needs further consideration.

In order to understand the above results, we analyze now the minimum scratch load promoting surface damage $\left(\mathrm{F}_{\text {th }}\right)$ presented in Figure $8 \mathrm{~b}$. We discard spurious conduct of $\mathrm{F}_{\text {th }}$ due to the unavoidable position dependence of scratch experiments in the polycrystalline material, by performing tests at different locations for each sample (repeated symbols in the figure). As expected, optical observation of the scratches, i.e., permanent damage, is detected earlier in the full length mirror Ref with a small variation with end load. For the graphene covered surfaces and, in particular for $S \_80, F_{\text {th }}$ increases with end load. In this context, Raman spectroscopy may help us to understand the damage mechanisms operating. As can be seen in Figure $8 \mathrm{c}$, whereas $\mathrm{I}_{\mathrm{G}} / \mathrm{I}_{\mathrm{SiCT}}$ shows a clear reduction along the scar (dark 
line in $\mathrm{G}$ image), $\mathrm{I}_{\mathrm{D}} / \mathrm{I}_{\mathrm{G}}$ significant increases (light line in $\mathrm{D} / \mathrm{G}$ image) as compared to the untested surrounding surface. This result allows inferring a partial loss of EG with the remaining becoming more defective. A more detailed analysis reveals a degradation mechanism dependent on the type of $\mathrm{SiC}$ face. In fact, a reduction of $46 \%$ in $\mathrm{I}_{\mathrm{G}} / \mathrm{I}_{\mathrm{SiCT}}$ was observed on the scratched zone relative to the untested Si-face grain (०) whereas it decreased by $78 \%$ for higher graphene content m/a-type faces $(\diamond)$. These results agree with a higher resistance to wear of the thin but strongly attached EG layers grown on Si-faces, which would justify a nearly constant contact area (i.e., the low slope of COF) and explain the higher $F_{\text {th }}$ of $S_{-} 80$, especially at high load $(50 \mathrm{mN})$, compared to S_20 that has more graphene grown over C-face grains. Conversely, detached graphene from MLG grown on $\mathrm{m} / \mathrm{a}$ - and C-grains would act as solid lubricant contributing to reduce friction. More data on damaging for different grains are presented in Figure S9 in the Supporting Information.

As derived from the above dependence of the EG characteristics (thickness, layer stacking, strain degree, coupling, wear resistance...) on the $\mathrm{SiC}$ grain orientation, one may question about the influence on the corresponding local electronic structure. In particular, the carbonaceous film grown in the $\mathrm{C}$-face can be viewed as decoupled and nearly free standing MLG that would, in principle, display transport properties and electronic behavior as independent monolayers $[55,63]$. We first note that as a consequence of the work function difference with the $\mathrm{SiC}$, graphene at the interface appears to be highly doped with an electron density typically of a few $\times 10^{12} \mathrm{~cm}^{2} \cdot \mathrm{V}^{-1} \cdot \mathrm{s}^{-1}[44]$. Moreover, unlike what happens for exfoliated graphene on $\mathrm{SiO}_{2}$ where surface potential builds up with thickness, approaching to a saturation value for about five or more graphene $[64,65]$, the charge density in $\mathrm{EG}$ on $\mathrm{SiC}$ remains mainly in the first layer above which charge neutrality is quickly reached [66]. Specifically, a contact potential value of $\sim 360 \mathrm{meV}$ has been reported for the graphene bilayer respect to the highly doped interfacial layer on $6 \mathrm{H}-\mathrm{SiC}(0001)$ single crystals [67]. In such a way, electronic differences are expected between the graphene films grown on the diverse SiC grains. 

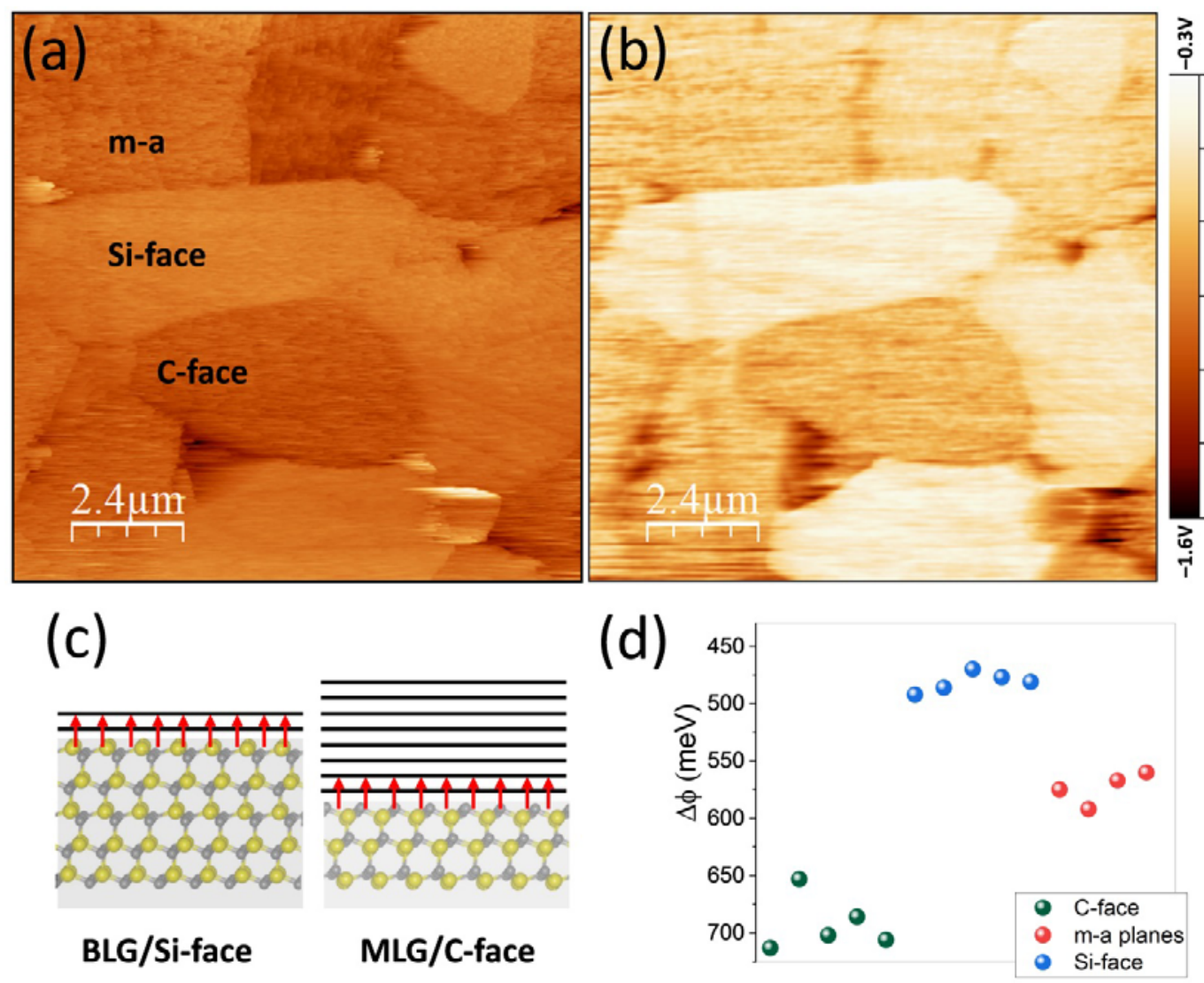

Figure 9. Topographic image (a), simultaneously surface potential (SP) map acquired by KPFM (b), model illustrating the differences in charge screening for BLG/Si-face and MLG/C-face (c) and estimated work function referred to that of the tip ( $\Delta \phi=\phi_{\text {sample }}-$ $\left.\phi_{\text {tip }}\right)$ for grains of different orientations in S_20 (d). Note: in our set-up the voltage is applied to the tip and areas with higher surface potential, i.e., brighter color in (b), correspond to lower work function $(\Delta \phi=-\mathrm{SP})$, see Supporting Information.

Figure 9 illustrates at glance the relationship between diverse grains identified in topography (Figure 9a) and the corresponding surface potential (SP) as measured by KPFM imaging (Figure 9b) on the S_20 SiC specimen. Each point of the work function difference $(\Delta \phi=-\mathrm{SP})$ plot shown in Figure 9c has been estimated by determining the peak position of the histogram of the KPFM image area of individual grains (see Figure S10 in the Supporting Information for analysis details). For each family of $\mathrm{SiC}$ grains, recognized by 
their morphological signature, $\Delta \phi$ are grouped around $475 \mathrm{meV}$ (Si-face), $575 \mathrm{meV}$ (m/aplanes) and $695 \mathrm{meV}$ (C-face), respectively. Differences in $\Delta \phi$ within a given family of planes are due to deviations respect to the nominal orientation, as sustained by similar results obtained for S_80 (not shown). Provided the local contact potential in epitaxial graphene on semiconductors is directly related to the carrier concentration, the notable difference of $\sim 220 \mathrm{meV}$ in average for the $\Delta \phi$ measured between grains evidences that charge neutrality has not been reached in the EG grown on the Si-face. This result is in agreement with the thinner graphene grown on this orientation ( 2 layers) as compared to that grown on the $\mathrm{C}$-face (at least 10 layers thick). In other words, due to the short decay length of charge density in $\mathrm{EG}$ on $\mathrm{SiC}$, the topmost layer of the BLG film on Si-face grains has a notable dopants level while it is fully screened by the underlying layers forming the MLG grown on C-face grains (Figure 9c). Though charge neutrality is also expected for the thick graphene grown on the non-polar grains, interpretation of the measured SP in this case may be obscured by charge trapping in the highly defective EG film (see Raman discussion).

The respective strong and weak coupling between substrate and the successive graphene layers grown under the same conditions on the basal Si- and $\mathrm{C}$ - planes of $\mathrm{SiC}$ confer upon the epitaxial graphene differentiated mechanical and electronic properties exemplified by specific structural features and carrier density. The quality and lateral continuity of the EG obtained by SPS on polycrystalline silicon carbide makes these materials promising for advanced applications in nanotechnology.

\section{Conclusions}

By using modified SPS tool dies, considerably smooth and continuous carpet-like epitaxial graphene (EG) films have been obtained over polycrystalline SiC materials with a series of differentiating surface characteristics depending on the grain orientation. As graphene film growth takes place under the same conditions, the EG growth in different $\mathrm{SiC}$ planes $(\mathrm{C}$ face, Si-face and $\mathrm{m} / \mathrm{a}$-faces) present at the surface has been analyzed at once by employing 
imaging techniques at diverse length scales, from optical and FESEM to SFM and microRaman tools.

Conversely to a quite amorphous like texture of non-polar grains, the strain energy landscape for polar planes leads to the occurrence of diverse structural peculiarities (from ripples or ridges to fringed or wrinkled patterns) which confer to the EG grown at these surfaces nearly ideal properties of BLG and MLG reported on Si- and C- oriented single crystals. The frictional properties at the nanoscale are highly homogeneous with only anisotropic consequences due to non-uniform puckering in the C-face or to groove channel orientation in grains of the $\mathrm{m}$-a plane family. The minimum load needed to detect perceptible surface damage by scratch testing decreases for the EG surfaces as compared to pristine $\mathrm{SiC}$, with a notable mechanical strength for the BLG while debris detached from MLG could act as solid lubricant reducing friction. In terms of electronic properties, the variability of the surface work function lies within the $0.2 \mathrm{eV}$ considering the whole $\mathrm{SiC}$ grains ensemble in agreement with the short decay length of charge density in EG on SiC.

Due to the inherent random orientation of the grains in a polycrystalline material, epitaxial graphene grown by SPS on the surface of dense polycrystalline silicon carbide constitutes a benchmark for properties tests. Moreover, on the one hand, the quality of the graphene films make the material fabricated by the SPS attractive for applications and, on the other hand, the SPS technique itself is demonstrated as a reliable and flexible methodology for preparing such graphene films on $\mathrm{SiC}$ components with real possibilities for scaling-up at low cost.

\section{Acknowledgments}

This work has been supported by the Spanish government under the projects MAT201567437-R (MICINN/FEDER, UE), MAT2016-77852-C2-1-R (AEI/FEDER, UE), RTI2018095052-B-100 and the "Severo Ochoa" Program for Centers of Excellence in R\&D (SEV2015-0496) and the Generalitat de Catalunya through grant 2017 SGR668. C. R. thanks the financial support by MICINN under contract IJCI-2017-34724 of "Juan de la Cierva" Program. The authors gratefully acknowledge A. del Campo for his help and advice in acquisition of Raman-AFM images. 


\section{Apendix A. Supplementary data}

Supporting Information. Methodological details of Friction Force Microscopy and Kelvin Probe Force Microscopy as well as additional SFM and Raman data are provided.

\section{References}

[1] Zhao, G.; Li, X.; Huang, M.; Zhen, Z.; Zhong, Y.; Chen, Q. et al. The physics and chemistry of graphene-on-surfaces. Chem. Soc. Rev. 2010, 46, 4417-4449.

[2] Chen, Y.; Gong, X. L.; Gai, J. G. Progress and Challenges in Transfer of Large-Area Graphene Films. Adv. Sci. 2016, 3, 1500343.

[3] Wu, Z. S.; Pei, S.; Ren, W.; Tang, D.; Gao, L.; Liu, B. et al. Field emission of singlelayer graphene films prepared by electrophoretic deposition. Adv. Mater. 2009, 21, 1756-1760.

[4] An, S. J.; Zhu, Y.; Lee, S. H.; Stoller, M. D.; Emilsson, T.; Park, S. et al. Thin film fabrication and simultaneous anodic reduction of deposited graphene oxide platelets by electrophoretic deposition. J. Phys. Chem. Lett. 2010, 1, 1259-1263.

[5] Reina, A.; Jia, X.; Ho, J.; Nezich, D.; Son, H.; Bulovic, V. et al. Large area, few-layer graphene films on arbitrary substrates by chemical vapor deposition. Nano Lett. 2009, 9, $0-35$.

[6] De Heer, W. A.; Berger, C.; Ruan, M.; Sprinkle, M.; Li, X.; Hu, Y. et al. Large area and structured epitaxial graphene produced by confinement controlled sublimation of silicon carbide. PNAS 2011, 108, 16900-16905.

[7] Yazdi, G.R.; Iakimov, T.; Yakimova, R. Epitaxial graphene on SiC: a review of growth and characterization. Crystals 2016, 6, 53.

[8] Roewer, G.; Herzog, U.; Trommer, K.; Müller, E.; Frühauf, S. Silicon carbide, a survey of synthetic approaches, properties and applications. In: High Performance Non-Oxide Ceramics I. Structure and Bonding 2002, vol. 101, 59-135. Springer, Berlin, Heidelberg.

[9] Kriegesmann, J. Processing of silicon carbide-based ceramics, in Comprehensive Hard Materials, vol.1, V.K. Sarin, D. Mari, L. Llanes (Eds.), Elsevier (2014), pp. 89-175. Elsevier Ltd. 
[10] Kim, K. S.; Lee, H. J.; Lee, C., Lee, S. K.; Jang, H.; Ahn, J. H. et al. Chemical vapor deposition-grown graphene: the thinnest solid lubricant. ACS Nano 2011, 5, 5107-5114.

[11] Liang, H.; Bu, Y.; Zhang, J.; Cao, Z.; Liang, A. Graphene oxide film as solid lubricant. ACS Appl. Mater. Interfaces 2013, 5, 6369-6375.

[12] Filleter, T.; McChesney, J. L.; Bostwick, A.; Rotenberg, E.; Emtsev, K. V.; Seyller, T. et al. Friction and dissipation in epitaxial graphene films. Phys. Rev. Lett. 2009, 102, 086102.

[13] Berman, D.; Erdemir, A.; Sumant, A. V. Graphene: a new emerging lubricant. Mater. Today 2014, 17 (2014) 31-42.

[14] Kim, S.; Kumar, M.; Keun, G.; Lee, Y.; Sohn, A.; Kim, T.Y. at al. Transparent Flexible Graphene Triboelectric Nanogenerators, Adv. Mater. 2014, 26, 3918-3925

[15] Dai, W.; Lv, L.; Lu, J.; Hou, H.; Yan, Q.; Alam, F.E. et al. A paper-like Inorganic Thermal Interface Material Composed of Hierarchically Structured Graphene/Silicon Carbide Nanorods, ACS Nano 2019, 13, 1547-1554.

[16] Munz, M.; Giusca, C.E.; Myers-Ward, R.L.; Gaskill, D.K.; Kazakova, O. ThicknessDependent Hydrophobicity of Epitaxial Graphene, ACS nano 2015, 9, 8401-8411.

[17] Huang, H.; Wong, S. L.; Tin, C.C.; Luo, Z. Q.; Shen, Z. X.; Chen, W. et al. Epitaxial growth and characterization of graphene on free-standing polycrystalline SiC. J. Appl. Phys. 2011, 110, 014308.

[18] Galvão, N. K.; Vasconcelos, G.; Dos Santos, M.V.R.; Tiago Moreira Bastos Campos, T.M.B.; Pessoa, R.S.; Guerino, M. et al. Growth and characterization of graphene on polycrystalline $\mathrm{SiC}$ substrate using heating by $\mathrm{CO}_{2}$ Laser beam. Mater. Res. 2016, 19, 1329-1334.

[19] Srivastava, N.; He, G.; Luxmi, Mende, P. C.; Feenstra, R. M.; Sun, Y. Graphene formed on $\mathrm{SiC}$ under various environments: comparison of Si-face and C-face. J. Phys D: Appl. Phys. 2012, 45, 154001.

[20] Daas, B. K.; Omar, S. U.; Shetu, S.; Daniels, K. M.; Ma, S.; Sudarshan, T. S. et al. Comparison of epitaxial graphene growth on polar and nonpolar $6 \mathrm{H}-\mathrm{SiC}$ faces: on the growth of multilayer films. Cryst. Growth Des. 2012, 12, 3379-3387.

[21] Sun, L.; Chen, X.; Yu, W.; Sun, H.; Zhao, X.; Xu, X. et al. The effect of the surface energy and structure of $\mathrm{SiC}$ substrate on epitaxial graphene growth. RSC Adv. 2016, 6, 100908 .

[22] Vasiliauskas, R.; Juillaguet, S.; Syväjärvi, M.; Yakimova, R. Cubic SiC formation on the C-face of 6H-SiC (0001) substrates. J. Crys. Growth 2012, 348, 91-96. 
[23] Shenoy, V. B.; Reddy, C. D.; Ramasubramaniam, A.; Zhang, Y. W. Edge-stressinduced warping of graphene sheets and nanoribbons. Phys. Rev. Lett. 2008, 101, 245501.

[24] Berger, C.; Song, Z.; Li, X.; Wu, X.; Brown, N.; Naud, C. et al. Electronic confinement and coherence in patterned epitaxial graphene. Science 2006, 312, 1191-1196.

[25] Biedermann, L. B.; Bolen, M. L.; Capano, M. A; Zemlyanov, D.; Reinfenberg, R. G. Insights into few-layer epitaxial graphene growth on $4 \mathrm{H}-\mathrm{SiC}(000-1)$ substrates from STM studies. Phys. Rev. B 2009, 79, 125411.

[26] Horcas, I.; Fernández, R.; Gómez-Rodríguez, J. M.; Colchero, J.; Gómez-Herrero, J.; Baro, A. M. WSXM: a software for scanning probe microscopy and a tool for nanotechnology. Rev. Sci. Instrum. 2007, 78, 013705.

[27] Carpick R.W.; Salmeron M. Scratching the surface: fundamental investigations of tribology with atomic force microscopy. Chem. Rev. 1997, 97, 1163-1194.

[28] Barth, C.; Foster, A. S.; Henry, C. R.; Shluger, A. L. Recent trends in surface characterization and chemistry with high-resolution scanning force methods. Adv. Mater. 2011, 23, 477-501.

[29] Nakashima, S.; Harima, H. Raman investigation of SiC polytypes. Phys. Stat. Sol. 1997, 162, 39-64.

[30] Miranzo, P.; López-Mir, L.; Román-Manso, B.; Belmonte, M.; Osendi, M. I.; Ocal, C. Prominent local transport in silicon carbide composites containing in-situ synthesized threedimensional graphene networks. J. Eur. Ceram. Soc. 2016, 36, 3073-3081.

[31] Liu, X.; Zhuo, S. Y.; Gao, P.; Huang, W.; Yan, C. F.; Shi, E. W. Donor- acceptor-pair emission in fluorescent 4H-SiC grown by PVT method. AIP Advances 2015, 5, 047133.

[32] Piluso, N.; Severino, A.; Camarda, M.; Anzalone, R.; Canino, A.; Condorelli, G. et al. Raman Characterization of Doped 3C-SiC/Si for Different Silicon Substrates and C/Si Ratios. Mater Sci Forum 2010, 645-648, 255-258.

[33] Muehlhoff, L.; Choyke, W. J.; Bozack, B. J.; Yates, J. T. Comparative electron spectroscopic studies of surface segregation on $\mathrm{SiC}$ (0001) and SiC (000-1). J. Appl. Phys. 1986, 60, 2842

[34] Jernigan, G. G.; Van Mil, B. L.; Tedesco, J. L.; Tischler, J. G.; Glaser, E. R.; Davidson, A. et al. Comparison of epitaxial graphene on Si-face and C-face 4H SiC formed by ultrahigh vacuum and RF furnace production. Nano Lett. 2009, 9, 2605-2609. 
[35] Ni, Z. H.; Chen, W.; Fan, X. F.; Kuo, J. L.; Yu, T.; Wee A. T. S. et al. Raman spectroscopy of epitaxial graphene on a SiC substrate. Phys. Rev. B 2008, 77, 115416.

[36] Robinson J. A.; Puls, C. P.; Staley, N. E.; Stitt, J. P.; Fanton, M. A.; Emtsev, K. V. et al. Raman topography and strain uniformity of large-area epitaxial graphene. Nano Lett., 2009, 9, 964-968.

[37] Li, Z.; Bradt, R. C. Thermal expansion and thermal expansion anisotropy of SiC polytypes. J. Am. Ceram. Soc. 1987, 70, 445-448.

[38] Tsang, D. K. L.; Marsden, B. J.; Fok, S. L.; Hall, G. Graphite thermal expansion relationship for different temperature ranges. Carbon, 2005, 43, 2902-2906.

[39] Shivaraman, S.; Chandrashekhar, M.V.S.; Boeckl, J.J.; Spencer, M. G. Thickness estimation of epitaxial graphene on $\mathrm{SiC}$ using attenuation of substrate Raman intensity. J. Elect. Mater. 2009, 38, 725-730.

[40] Röhrl, J.; Hundhausen, M.; Emtsev, K. V.; Seyller, T.; Graupner, R.; Ley, L. Raman spectra of epitaxial graphene on $\mathrm{SiC}$ (0001). Appl. Phys. Lett. 2008, 92, 201918.

[41] Lee, D. S.; Riedl, C.; Krauss, B.; von Klitzing, K.; Starke, U.; Smet, J. H. Raman spectra of epitaxial graphene on $\mathrm{SiC}$ and of epitaxial graphene transferred to $\mathrm{SiO}_{2}$. Nano Letters 2008, 8, 4320-4325.

[42] Prakash, G.; Capano, M.A.; Bolen, M.L.; Zemlyanov, D.; Reifenberger, R.G. AFM study of ridges in few-layer epitaxial graphene grown on the carbon-face of $4 \mathrm{H}-\mathrm{SiC}(000$ 1). Carbon 2010, 48, 2383-2393.

[43] Emtsev, K. V.; Speck, F.; Seyller, T.; Ley, L.; Riley, J. D. Interaction, growth, and ordering of epitaxial graphene on $\mathrm{SiC}\{0001\}$ surfaces: A comparative photoelectron spectroscopy study. Phys. Rev. B 2008, 77, 155303.

[44] First, P. N.; de Heer, W. A.; Seyller, T.; Berger, C.; Stroscio, J. A., Moon, J. S. Epitaxial graphenes on Silicon Carbide. MRS Bulletin 2010, 35, 296-305.

[45] Riedl, C.; Coletti, C.; Starke, U. Structural and electronic properties of epitaxial graphene on $\mathrm{SiC}(0001)$ : a review of growth, characterization, transfer doping and hydrogen intercalation. J. Phys. D: Appl. Phys. 2010, 43, 374009.

[46] Bostwick, A.; McChesney, J.; Ohta, T.; Rotenberg, E.; Seyller, T.; Horn, K. Experimental studies of the electronic structure of graphene. Prog. Surf. Sci. 2009, 84, 380 413. 
[47] Deng, S.; Berry, V. Wrinkled, rippled and crumpled graphene: an overview of formation mechanism, electronic properties, and applications. Mater. Today 2016, 19, $197-212$.

[48] Vecchio, C.; Sonde, S.; Bongiorno, C.; Rambach, M.; Yakimova, R.; Rainieri, V. et al. Nanoscale structural characterization of epitaxial graphene grown on off-axis $4 \mathrm{H}-\mathrm{SiC}$ (0001). Nanoscale Res. Lett. 2011, 6, 269.

[49] Sun G. F.; Jia, J. F.; Xue, Q. K.; Li, L. Atomic-scale imaging and manipulation of ridges on epitaxial graphene on 6H-SiC (0001). Nanotechnology 2009, 20, 355701.

[50] Seung, H. S.; Nelson, D. R. Defects in flexible membranes with crystalline order. Phys. Rev. A Gen. Phys. 1998, 38, 1005-1018.

[51] Harrison S.E., Capano, M. A. Riefenberger R. Scanning tunneling microscope study of striated carbon ridges in few -layer epitaxial graphene formed on $4 \mathrm{H}$-silicon carbide $(000$ 1) Appl. Phys. Lett. 2010, 96, 081905.

[52] Seyller, T.; Emtsev, K. V.; Gao, K.; Speck, F.; Ley, L.; Tadich, A. et al. Structural and electronic properties of graphite layers grown on $\mathrm{SiC}\left(\begin{array}{lll}0 & 0 & 1\end{array}\right)$. Surf. Sci. 2006, 600, 3906-3911.

[53] Luxmi; Fisher, P. J.; Srivastava, N.; Feenstra, R. M.; Sun, Y.; Kedzierski J. et al. Morphology of graphene on SiC (000-1) surfaces. Appl. Phys. Lett. 2009, 95, 073101.

[54] Luxmi, Srivastava, N.; He, G.; Feenstra, R. M.; Fisher, P. J. Comparison of graphene formation on C-face and Si-face SiC $\{0001\}$ surfaces. Phys. Rev. B 2010, 82, 235406.

[55] Hass, J.; Varchon, F.; Millán-Otoya, J. E.; Sprinkle, M.; Sharma, N.; De Heer, W. A. et al. Why multilayer graphene on $4 \mathrm{H}-\mathrm{SiC}(000-1)$ behaves like a single sheet of graphene. Phys. Rev. Lett. 2008, 100, 125504.

[56] Choudhary, S. K.; Gupta, A.K. Spatially varying super-lattice structures and linear fringes on graphite surface. J. Phys.: Condens. Matter 2008, 20, 225008.

[57] Udupa, A.; Martini, A. Model predictions of shear strain-induced ridge defects in graphene. Carbon 2011, 49, 3571-3578.

[58] Lee, C.; Li, Q.; Kalb, W.; Liu, X.-Z.; Berger, H.; Carpick, R.W. et al. Frictional characteristics of atomically thin sheets. Science 2010, 328, 76-80.

[59] Li, S.; Li, Q.; Carpick, R. W.; Gumbsch, P.; Liu, X. Z.; Ding, X. et al. The evolving quality of frictional contact with graphene. Nature 2016, 539, 542-545. 
[60] Choi, J. S.; Kim, J. S.; Byun, I. S.; Lee, D. H.; Lee, M. J.; Park, B.H. et al. Friction Anisotropy-Driven Domain Imaging on Exfoliated Monolayer Graphene. Science 2011, 333, 607-610.

[61] Lee, H.; Lee, N.; Seo, Y.; Eom, J.; Lee, S. W. Comparison of frictional forces on graphene and graphite. Nanotechnology 2009, 20, 325701.

[62] Lin, L.-Y.; Kim, D.-E.; Kim, W.-K.; Jun, S.-C. Friction and wear characteristics of multi-layer graphene films investigated by atomic force microscopy. Surf. Coat. Technol. 2011, 205, 4864-4869.

[63] Sprinkle, M.; Siegel, D.; Hu, Y.; Hicks, J.; Tejeda, A.; Taleb-Ibrahimi, A. et al. First direct observation of a nearly ideal graphene band structure. Phys Rev. Lett. 2009, 103, 226803.

[64] Ziegler, D.; Gava, P.; Güttinger, J.; Molitor, F.; Wirtz, L.; Lazzeri, M. et al. Variations in the work function of doped single-and few-layer graphene assessed by Kelvin probe force microscopy and density functional theory. Phys. Rev. B 2011, 83, 235434.

[65] Datta, S. S.; Strachan, D. R.; Mele, E. J.; Johnson, A. T. C. Surface potentials and layer charge distributions in few-layer graphene films, Nano Lett. 2009, 9, 7-11.

[66] Lauffer, P.; Emtsev, K. V.; Graupner, R.; Seyller, T.; Ley, L.; Reshanov, S. A. et al. Atomic and electronic structure of few-layer graphene on $\mathrm{SiC}(0001)$ studied with scanning tunneling microscopy and spectroscopy. Phys. Rev. B 2008, 77, 155426.

[67] Filleter, T.; Emtsev, K. V.; Seyller, T.; Bennewitz, R. Local work function measurements of epitaxial graphene. Appl. Phys. Lett 2008, 93, 133117. 


\title{
Supporting Information
}

\section{Face dependent footprints of carpet-like graphene films grown on polycrystalline silicon carbide}

\author{
C. Ramírez, ${ }^{1}$ E. García, ${ }^{1 \S}$ E. Barrena, ${ }^{2}$ A. De Pablos, ${ }^{1}$ M. Belmonte, ${ }^{1}$ M.I. Osendi, ${ }^{1}$ \\ P. Miranzo, ${ }^{1 *}$ C. $\mathrm{Ocal}^{2 \dagger}$ \\ ${ }^{1}$ Instituto de Cerámica y Vidrio (ICV-CSIC), Campus de Cantoblanco, 28049 Madrid, Spain \\ ${ }^{2}$ Institut de Ciència de Materials de Barcelona (ICMAB-CSIC) \\ Campus UAB, 08193 Bellaterra, Barcelona, Spain
}

${ }^{\S}$ Present address: Center for Thermal Spray Research, Stony Brook University, Stony Brook, 11794-2275, NY, USA.

* Corresponding author: Tel:+34-917355840 E-mail: pmiranzo@icv.csic.es (Pilar Miranzo)

+ Corresponding author: Tel:+34-935801853. E-mail: cocal@icmab.es (Carmen Ocal) 
Friction Force Microscopy (FFM). During tip scanning in SFM contact mode operation, in addition to cantilever normal deflection (topography), the cantilever torsion is monitored as a lateral deflection of the reflected laser beam. Since the lateral force caused by friction always opposes the tip motion, the tip twist reverses when the scan direction is inverted. Consequently, if a surface consists of regions with different friction, lateral force images will present opposite contrast in forward and backward directions. Those regions of lower friction would appear as dark patches in the forward and brighter in the backwards scans, respectively. The local friction signal is defined as half the amplitude of the so called friction loop, $\mathrm{F}=1 / 2\left(F l_{\mathrm{f}}-\mathrm{Fl}_{\mathrm{b}}\right)$, where $F \mathrm{l}_{\mathrm{i}}$ is the lateral force signal of the forward (i=f) and the corresponding backward (i=b) scans. Friction anisotropy (AN) refers to the variation of the friction coefficient with the relative orientation of sliding surfaces and is commonly correlated with the azimuthal orientation of a crystalline surface. As a consequence AN is observed as a different contrast but not inverted signal in forward and backward images. AN for graphene has been already reported [1,2].

Kelvin probe force microscopy (KPFM). KPFM is a dynamic mode which measures the so called contact potential difference or Surface Potential (SP) through measurement of the electrostatic force between a metallic tip and the sample. Contrary to CSFM, during KPFM the tip and sample are not in direct contact but electrically connected via electronics. As a result, their Fermi levels align creating a SP and thus a tip-sample electrostatic force develops. Though the method has been applied to a wide variety of materials, including insulators, KPFM was first introduced to investigate the work function of metals and it is understood as follows. If the work function of the KPFM tip (vibrating electrode) is $\varphi_{\text {tip }}$ and $\varphi_{\text {sample }}$ is that of the sample, then the contact potential difference between tip and sample is $\operatorname{SP}_{\text {sample }}=\left(\varphi_{\text {tip }}-\varphi_{\text {sample }}\right) / e=\Delta \varphi_{s} / e$, where $e$ is the electric charge. The tip, which is at some distance $(\sim 15 \mathrm{~nm})$ above the sample surface, is driven by an oscillating voltage $\mathrm{V}_{\text {tip }}=\mathrm{V}_{\mathrm{dc}}+\mathrm{V}_{\mathrm{ac}} \sin (\omega \mathrm{t})$ and, as a consequence, the electrostatic force between them is $F_{e s}=-\frac{1}{2} \frac{\partial c}{\partial z}\left[\left(V_{d c}-\Delta \varphi_{s} / e\right)+V_{a c} \sin (\omega t)\right]^{2}$, such that the $\mathrm{V}_{\mathrm{dc}}$ nullifying the first harmonic of this electrostatic force is just the $\mathrm{SP}_{\text {sample }}$. Often, as in the present work, in order to minimize cantilever contributions, the same minimization procedure is used but applied to the force gradient measurement: 


$$
\frac{\partial F_{e s}}{\partial z}=-\frac{\partial^{2} C}{\partial z^{2}}\left[\left(V_{d c}-\Delta \varphi_{s} / e\right)+V_{a c} \sin (\omega t)\right]^{2}
$$

And

$$
\frac{\partial F_{\omega}}{\partial z}=-\frac{\partial^{2} C}{\partial z^{2}}\left(V_{d c}-\Delta \varphi_{s} / e\right) V_{a c} \sin (\omega t)
$$

Where $F_{\omega}$ is the $\omega$ component of $F_{\text {es. }}$ In principle, knowing $\phi_{t i p}$, $\phi_{\text {sample }}$ can be calculated, but if the sample surface has regions with different electronic properties, as the case presented here, the contact potential of each region would be given by $\mathrm{SP}_{A}=\left(\varphi_{t i p}-\varphi_{A}\right) / e$ and $\operatorname{SP}_{B}=\left(\varphi_{t i p}-\varphi_{B}\right) / e$, respectively. Consequently, the contact potential difference between them is $\Delta \mathrm{SP}=\mathrm{SP}_{A}-\mathrm{SP}_{B}=$ $-\left(\varphi_{A}-\varphi_{B}\right)$ independently of the material the tip is made of. Therefore, the contrast of the surface potential maps obtained by scanning the tip over the surface directly reflects the local variations of the surface work function. The method lacks of nanometric lateral resolution but avoids problems derived from tip details (end atoms and geometry) appearing when attempting to determine absolute SP values. In KPFM imaging, the contrast of the surface potential maps obtained by scanning the tip over the surface directly gives quantification of the local variations of the surface work function. Note that by definition, the higher the local SP the lower the local effective work function $(\Delta \mathrm{SP}=-$ $\left.\Delta \varphi_{A B}\right)$. 


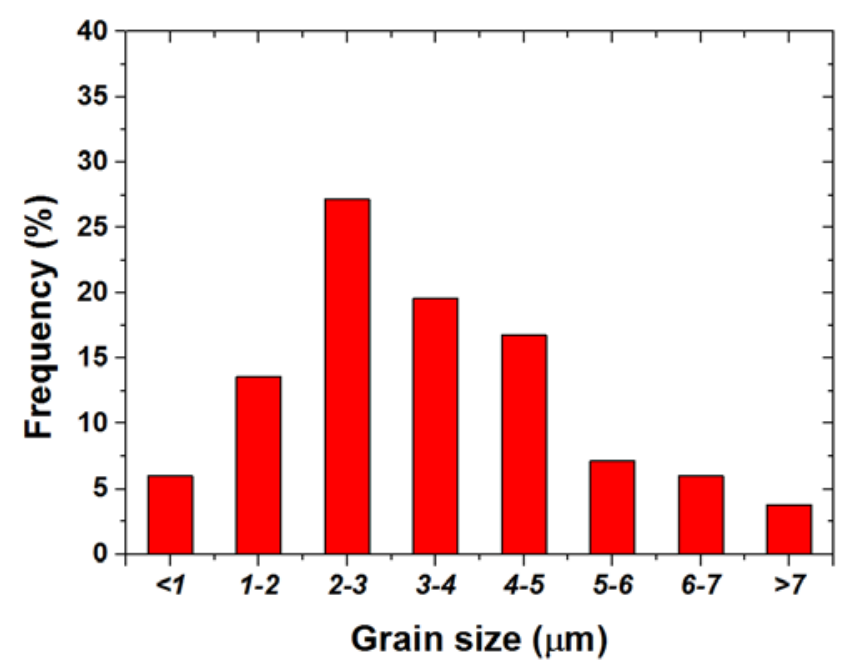

Figure S1. Grain size distribution of the polycrystalline SiC substrate (FWHM $\approx 5 \mu \mathrm{m}$ and mean grain size of $3.4 \mu \mathrm{m}$ ) as measured by image analysis on SEM micrographs of $60 \mu \mathrm{m} \times 40 \mu \mathrm{m}$.
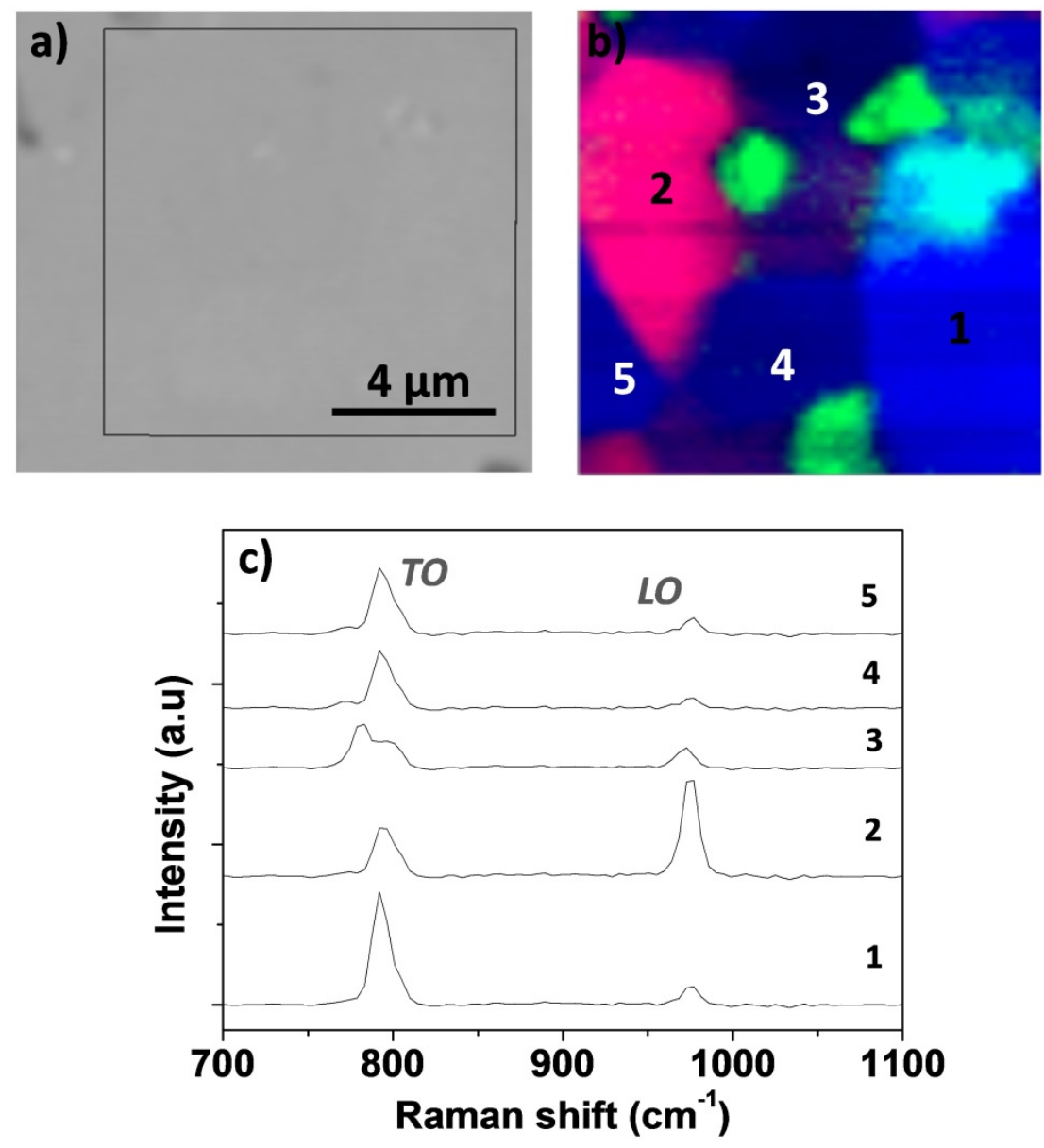

Figure S2. (a) Optical microscopy image of the polished pristine surface. (b) Merged intensity maps from TO (blue), LO (red) bands from SiC and G (green) peak from carbonaceous particles (c) Raman spectra of the different SiC grains found in the area. The positions of the bands correspond mainly to $6 \mathrm{H}-\mathrm{SiC}$ and $4 \mathrm{H}$ polytypes, spectrum 3 in (c). The images size is $(10 \mu \mathrm{m} \times 10 \mu \mathrm{m})$. The average spectrum shown in Figure 2c of the main manuscript was obtained from the same area. 

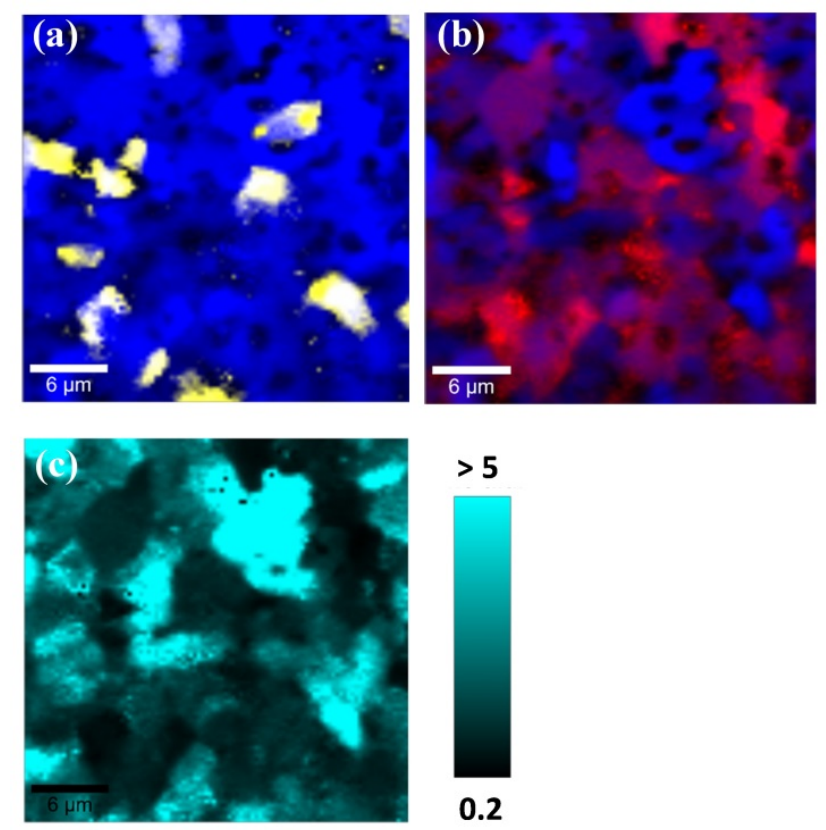

Figure S3. Raman $30 \times 30 \mu \mathrm{m}^{2}$ scan of SiC substrate. (a) In this case the intensity of the band at $793 \mathrm{~cm}^{-1}$, showing distribution of polytype $4 \mathrm{H}$ is represented in bright yellow, and $6 \mathrm{H}$-SiC polytype in blue. (b) $\mathrm{SiC}$ grains with intense $\mathrm{TO}$ band in blue and those with intense $\mathrm{LO}$ band in red. Areas in purple are associated to grains were intensity of TO and LO bands are similar. (c) Map of ratio $\mathrm{I}_{\mathrm{TO}} /$ $\mathrm{I}_{\mathrm{LO}}$. Either for monolithic $\mathrm{SiC}$ as for treated samples, grain surfaces presented $\mathrm{I}_{\mathrm{TO}} / \mathrm{I}_{\mathrm{LO}}$ mainly in the range 1-2.
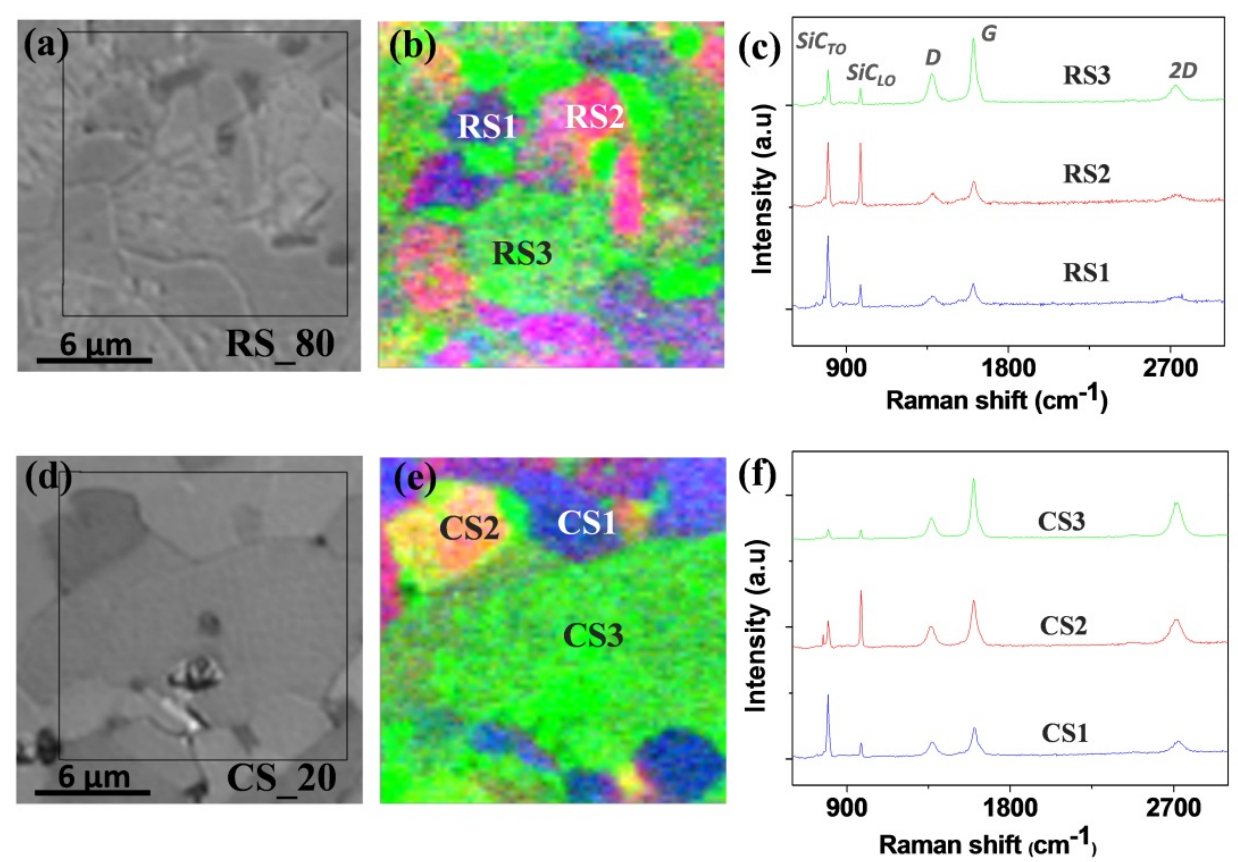

Figure S4. Optical micrographs, Raman spectroscopy maps and spectra for EG growth on S_80 (a), (b) and (c) and S_20. (d), (e) and (f). In treated samples optical images do show the grain distribution due to different Si sublimation rates, roughness and thickness of graphene film. The color code of the Raman intensity maps in (b) and (e) is: Blue for SiC TO, red for SiC LO and green for graphene $\mathrm{G}$ band. 

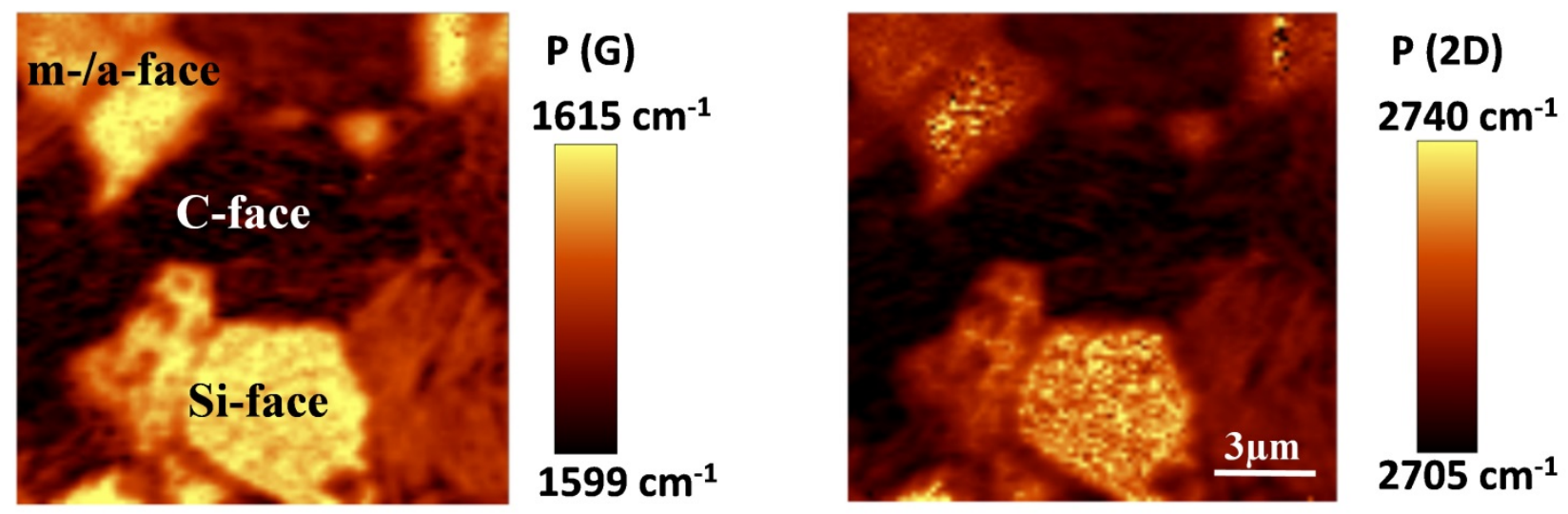

Figure S5. G and 2D peak position distribution for the area scanned in Fig. 3. The grain identified as Si-face presents the highest band shift associated to a growth of less than 3 layers.
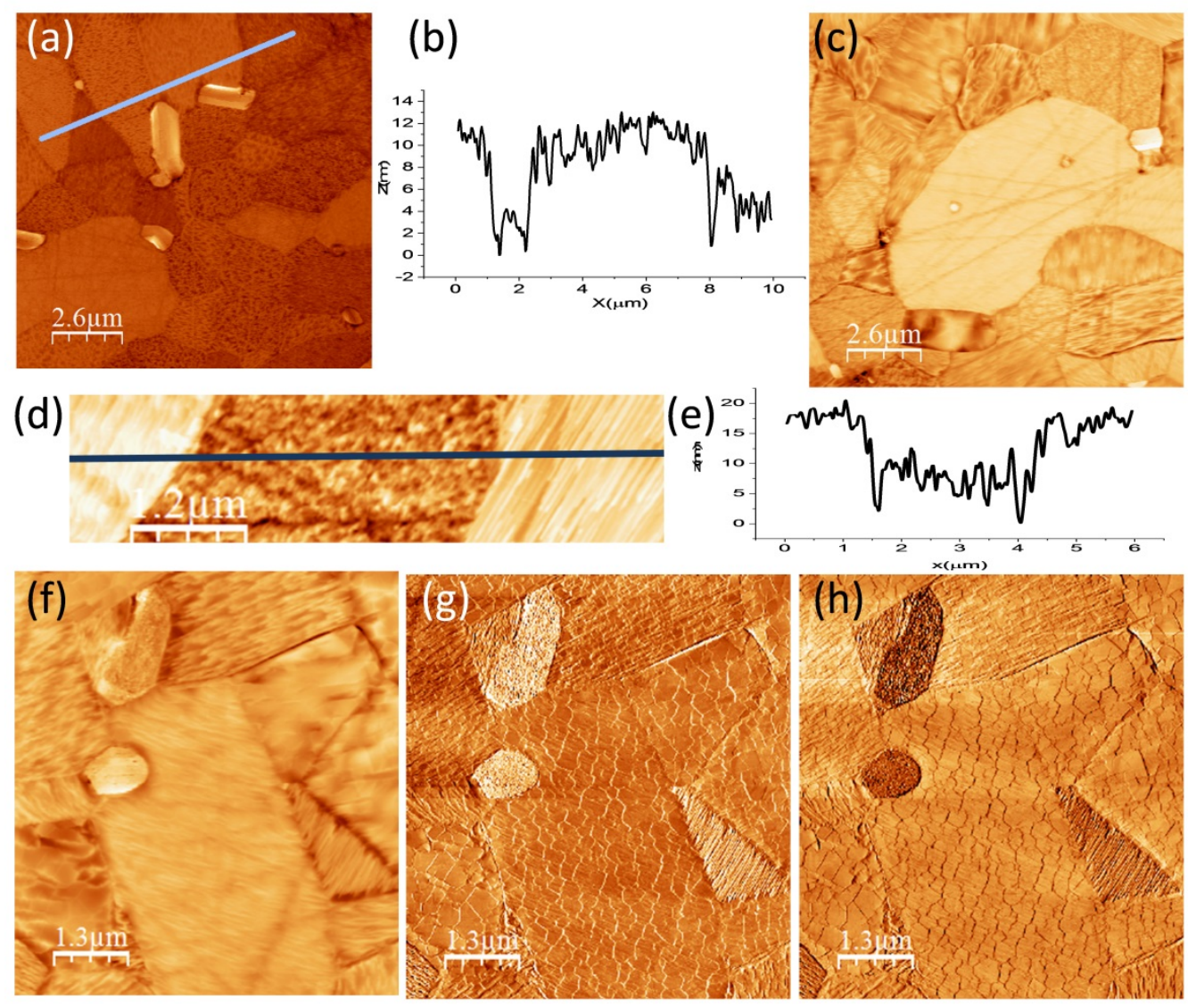

Figure S6. SFM data for two treated SiC specimens. (a) Large scale topographic image of S_20, (b) line profile along the segment indicated in (a) showing a recession of $\sim 10 \mathrm{~nm}$ between adjacent grains. (c)-(h) correspond to S-80: (c) Large scale topographic image where, in addition to the recognizable texture of diverse $\mathrm{SiC}$ grains, polishing lines are visible. (d) Topography and (e) corresponding profile crossing a m/a-surface surrounded by two Si-face grains. (f) Topography and simultaneous lateral force (g) forward and (h) backwards. Note the coexistence of highly stepped and faceted grains covered by a ripples network. 


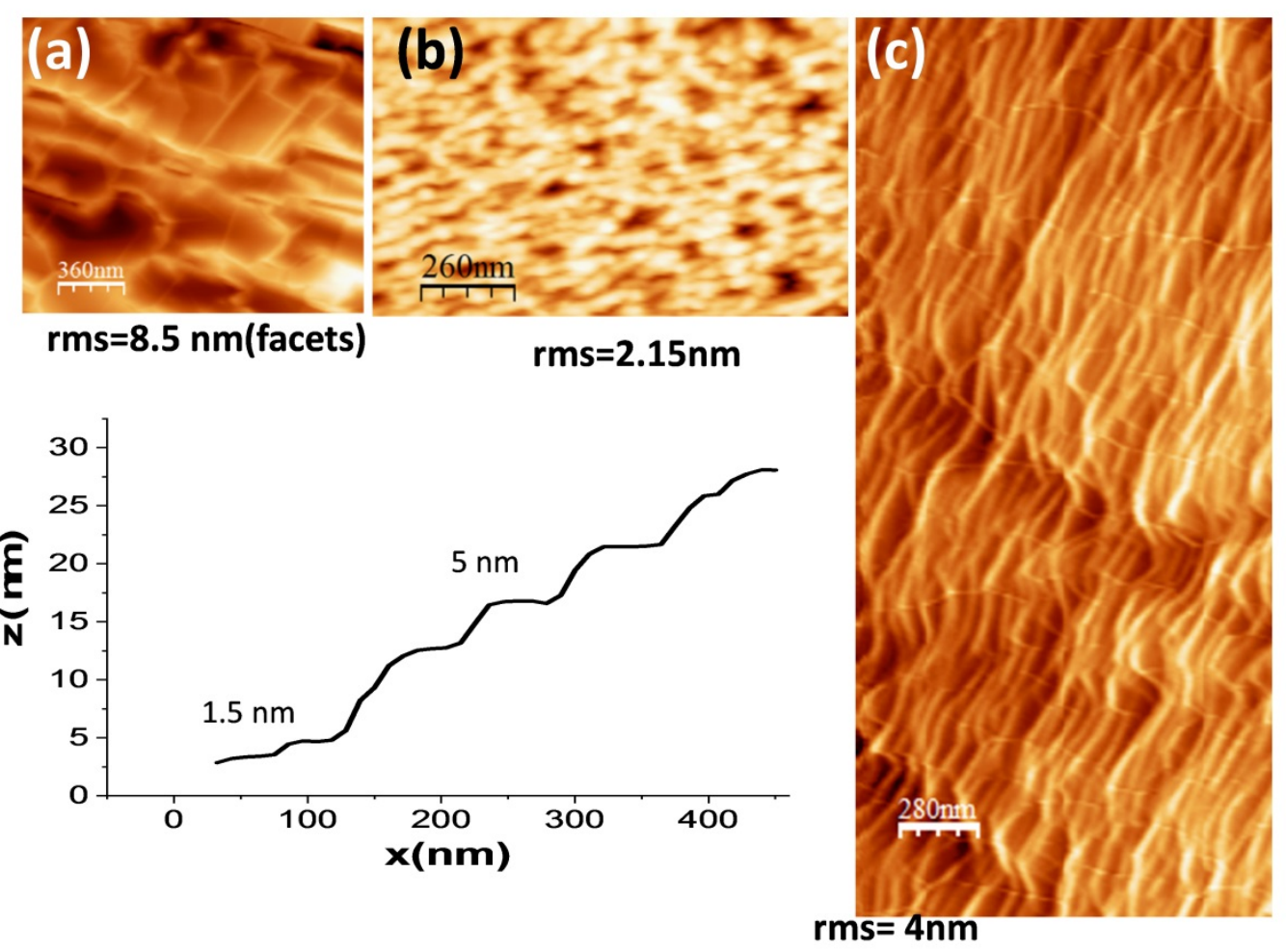

Figure S7. Topographic images of EG on SiC grains of different orientations in S_80: (a) C-face, with a faceted surface and rms $=8.5 \mathrm{~nm}$, (b) m/a- plane, with a certain groove orientation in an otherwise amorphous like surface with $\mathrm{rms}=2.6 \mathrm{~nm}$ and (c) Si-face with rms $=4 \mathrm{~nm}$ due to a high density of steps where the fine ripples network covering as a carpet like film the whole surface can be seen. The line profile corresponds to the stepped Si-face.

Table S1. Type of defects determined from Raman average spectrum of EG films over the different grain types in Figure 3 of the manuscript according to Eckmann et al. [3], where D' is a double resonance band associated to defects located close to $\mathrm{G}$ band at $\sim 1620 \mathrm{~cm}^{-1}$. The last column includes and estimation of defects density for C-face EG film using the relation found by Cançado et al. [4]

\begin{tabular}{|l|l|l|l|l|l|}
\hline & \multicolumn{4}{l|}{ Eckmann, 2012 [3] } & Cançado 2011 [4] \\
\hline $\begin{array}{l}\text { Grain surf. } \\
\text { type }\end{array}$ & ID/ID' & ID/IG & ID'/IG & Type of defect & nd $\left(\mathrm{cm}^{-2}\right)$ \\
\hline Si-face & 17 & 0.59 & 0.034 & $\mathrm{sp}^{3}$ & \\
\hline m-face & 19 & 0.93 & 0.048 & $\mathrm{sp}^{3} /$ vacancy & \\
\hline C-face & 4.8 & 0.96 & 0.20 & vacancy/boundary & $2.16 \mathrm{E} 11$ \\
\hline
\end{tabular}


The role of point and extended defects on friction has been largely explored. According to Gajurel et al. [5] the presence of vacancies can make the graphene sheet prone to pucker at the contact edge, which increases the contact area and thus leads to a larger friction. In particular, Zeng et al. [6] found that by increasing the surface adhesion of substrates, the friction of graphene could be significantly reduced due to suppressed puckering. The observation of puckering and a larger presence of vacancies might imply higher friction for C-face grains. In any case, m-face would show the highest friction because of the presence of vacancies in agreement with results shown in Figure 8c and 8d, where degradation depends on the type of SiC face with reductions in $\mathrm{I}_{\mathrm{G}} / \mathrm{I}_{\mathrm{SiCT}}$ on the scratched zone relative to the untested grain of $46 \%$ and $78 \%$ for the Si-face and m/a-type faces, respectively. However, no definite conclusion can be made only analyzing point defects since, as it has been mentioned in the manuscript, surface friction at the nanometer scale can be influenced by other diverse factors as non-homogeneous graphene thickness and differences in coupling with the substrate but also may arise from a non-uniform strain in the respective layers and, in particular, puckering and out-of-plane floppiness occurring during sliding.
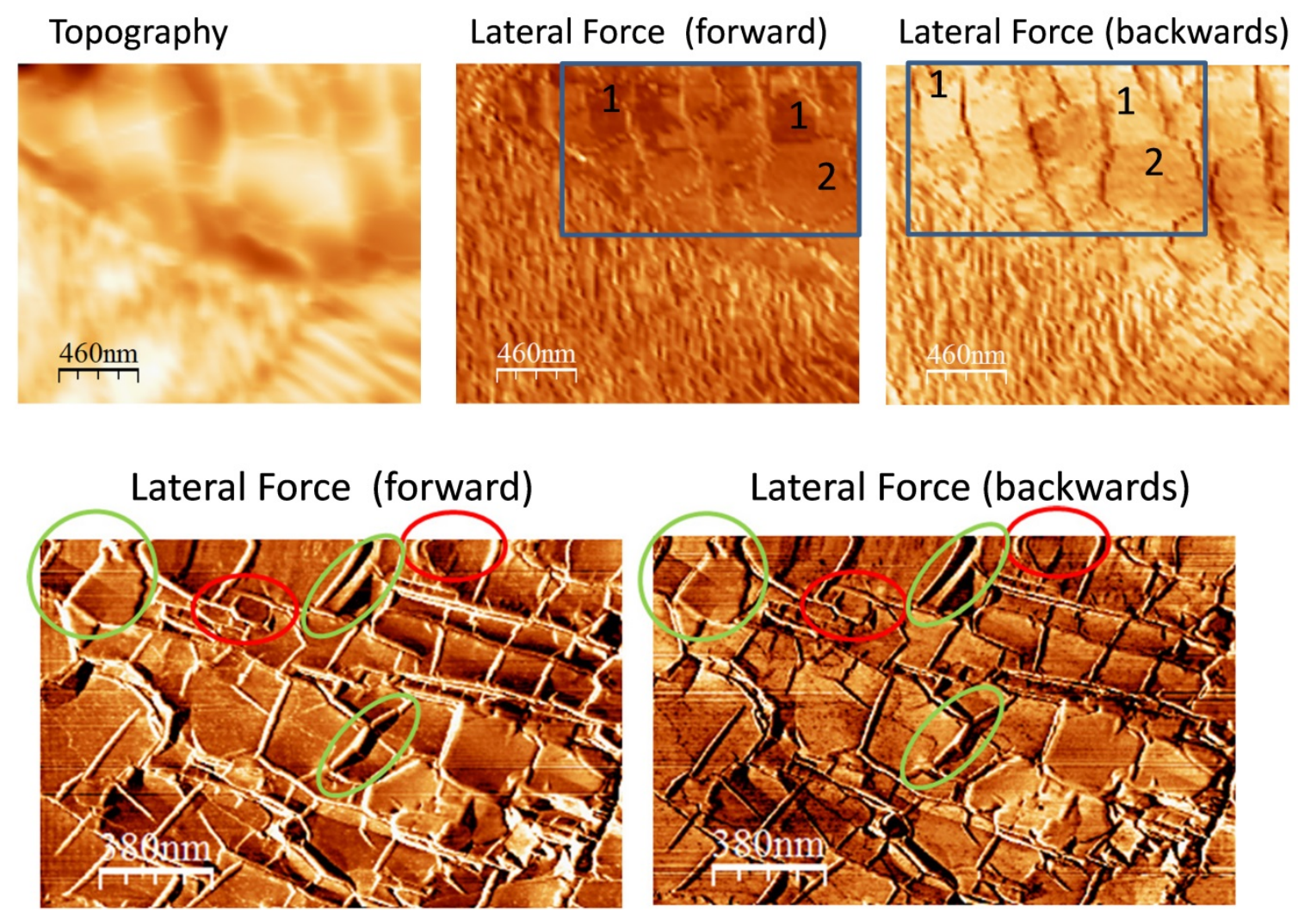

Figure S8. Top panels: topography and lateral force images. As reference, some regions have been labeled with numbers. Lower panels, regions with different friction have been encircled in red whereas regions exhibiting friction anisotropy (AN) in green. 

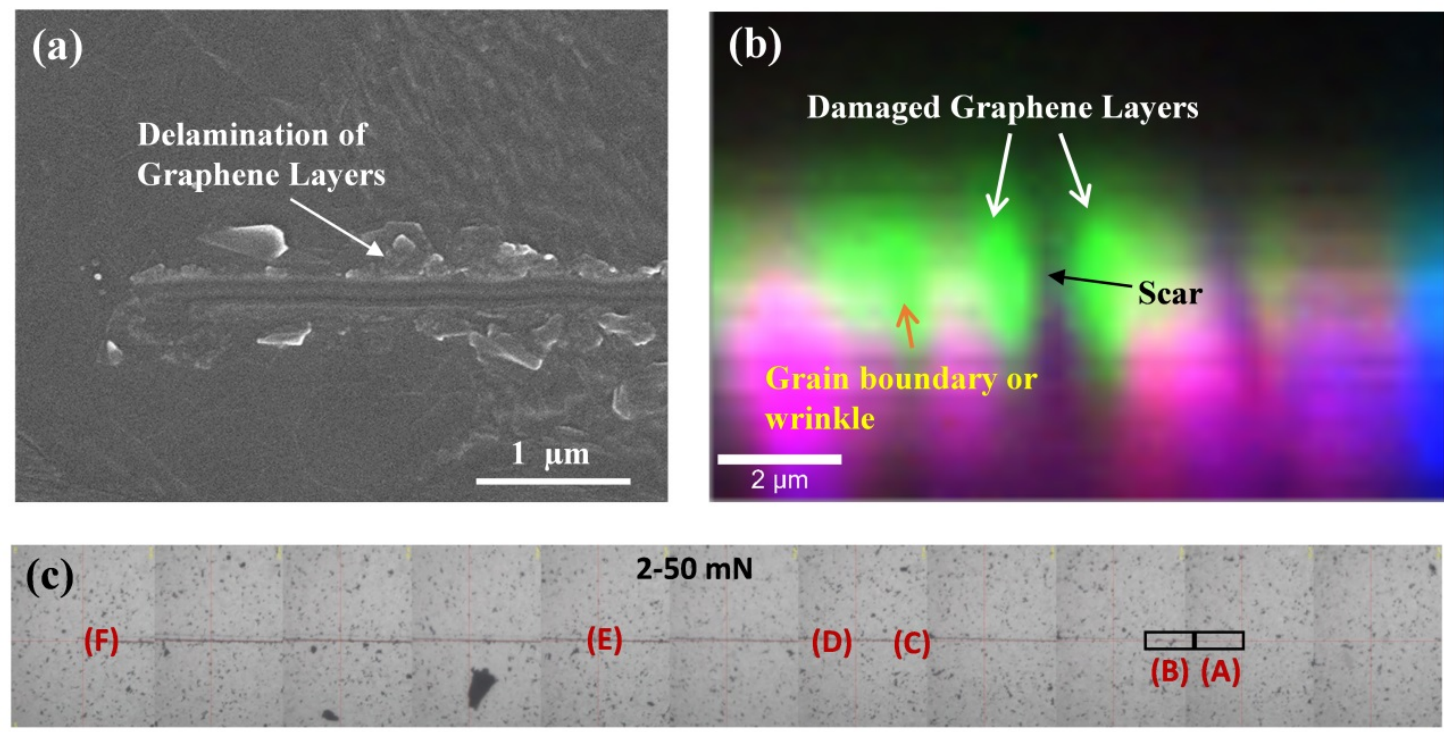

(d)
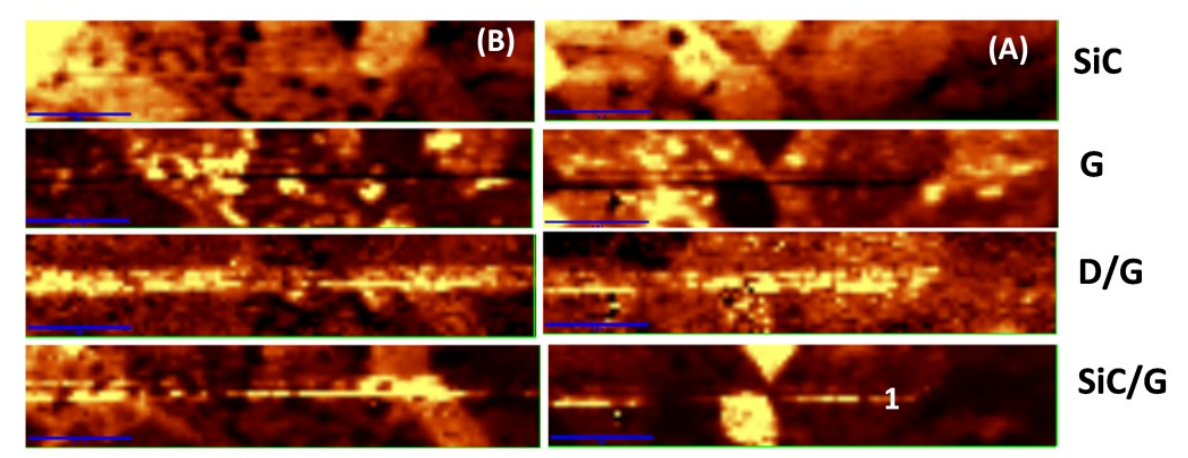

(e)

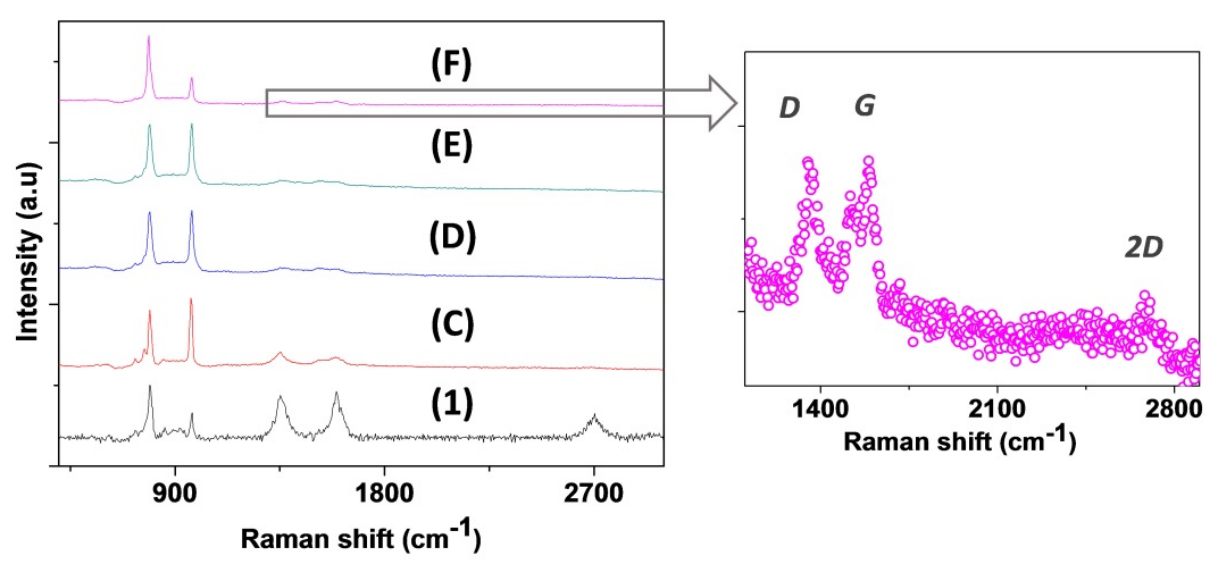

Figure S9. (a) SEM micrograph of scratch scar on EG grown on two grains with different orientations. Delimitation of EG is seen at both sides of scar. (b) Depth profile Raman map of a scratch scar. D band (green) shows the highest intensity for the delaminated material. Purple areas are associated to $\mathrm{SiC}$ and come from the combination of $\mathrm{SiC}$-TO (blue) and $\mathrm{SiC}$-LO (red) bands. (c) Optical composition of a scratch test where different Raman measurements were performed on the labeled positions. (d) Raman images from first $45 \mu \mathrm{m}$ of the scratch in (c) and corresponding to regions (A) and (B). Different bands were selected to show SiC grains, graphene G intensity and damage produced during test. (e) Single spectra from positions indicated in (c) and (d). A magnification on the graphene signal at the end of the test is also shown. 

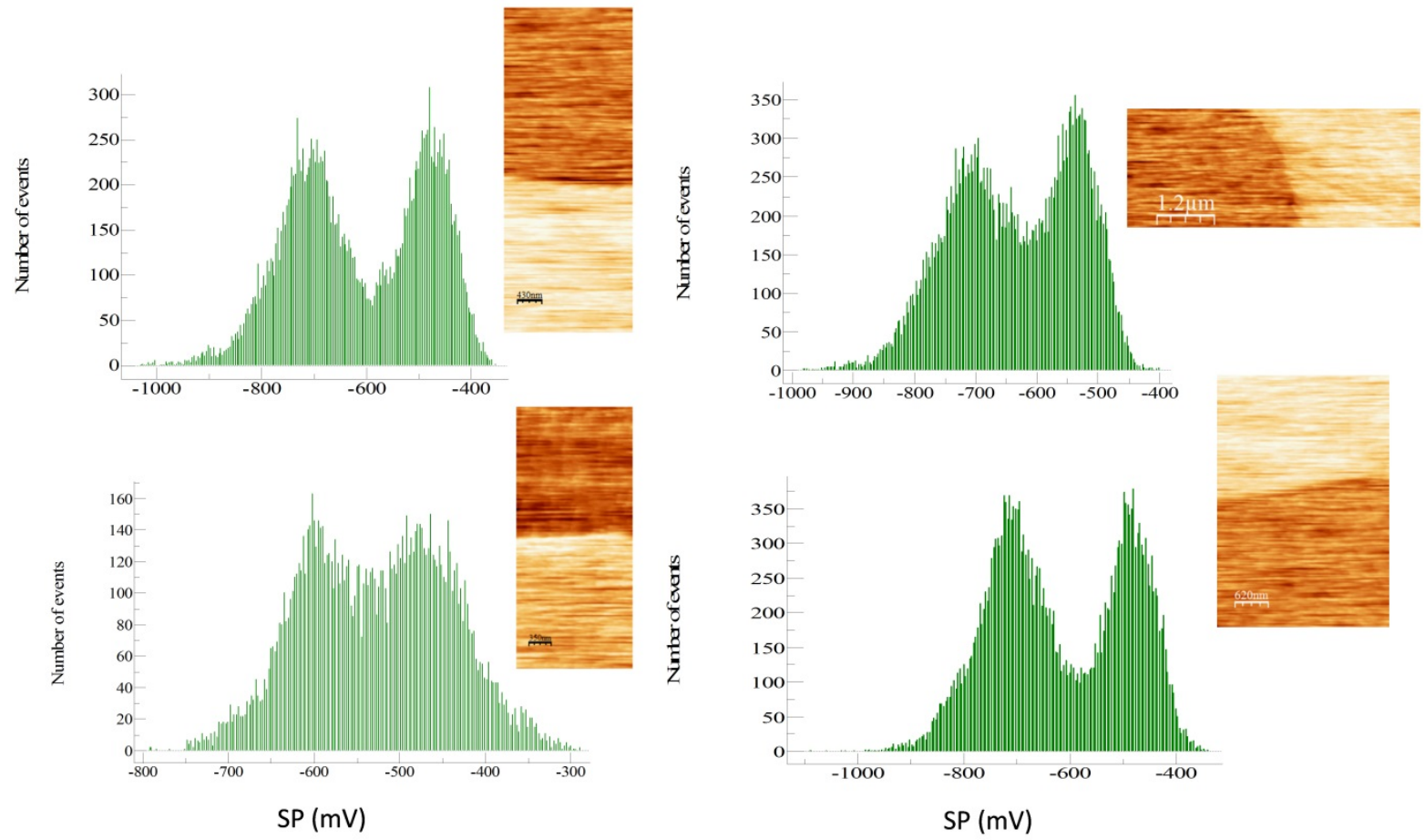

Figure S10. The work function analysis for the different families of SiC grains is made by determining the peak position (Gaussian fit) of the histograms of the KPFM images. As it can be seen in this figure, for areas containing grains of different family, two peaks are perfectly resolved despite their relatively large FWHM.

\section{REFERENCES}

[1] Almeida, C.M et al. Giant and Tunable Anisotropy of Nanoscale Friction in Graphene Scientific Reports 2016, 6, 31569.

[2] Choi, J. S.; Kim, J. S.; Byun, I. S.; Lee, D. H.; Lee, M. J.; Park, B.H. et al. Friction Anisotropy-Driven Domain Imaging on Exfoliated Monolayer Graphene. Science 2011, 333, 607-610.

[3] Eckmann, A. et al. Probing the nature of defects in graphene by Raman spectroscopy. Nano letters, 2012, 12, 3925-3930.

[4] Cançado, L.G.; Jorio, A.; Martins Ferreira, E.H.; Stavale, F.; Achete, C.A.; Capaz, R.B. et al. Quantifying defects in graphene via Raman spectroscopy at different excitation energies. Nano lett., 2011, 11, 8, 3190-3196.

[5] Gajurel, P.; Kim, M.; Wang, Q.; Dai, W.; Liu, H.; Cen, Ch. Vacancy-Controlled Contact Friction in Graphene, Adv. Funct. Mater. 2017, 27, 1702832.

[6] Zeng, X.; Peng, Y. ; Lang, H. A novel approach to decrease friction of graphene. Carbon 2017, $118,233-240$. 